\title{
Insights into Molecular Structures and Optical Properties of Stacked $\left[\mathrm{Au}-3\left(\mathrm{RN}=\mathrm{CR}{ }^{\prime}\right)(3)\right](\mathrm{n})$ Complexes
}

\section{Rabaa, Hassan}

2018-01-15

Rabaa , H , Omary , M A , Taubert , S \& Sundholm , D 2018 , ' Insights into Molecular Structures and Optical Properties of Stacked $\left[A u-3\left(R N=C R^{\prime}\right)(3)\right](n)$ Complexes ' , Inorganic Chemistry , vol. 57 , no. 2 , pp. 718-730 . https://doi.org/10.1021/acs.inorgchem.7b02593

http://hdl.handle.net/10138/309503

https://doi.org/10.1021/acs.inorgchem.7b02593

unspecified

acceptedVersion

Downloaded from Helda, University of Helsinki institutional repository.

This is an electronic reprint of the original article.

This reprint may differ from the original in pagination and typographic detail.

Please cite the original version. 


\title{
Insights into molecular structures and optical properties of stacked $\left[\mathbf{A u}_{3}\left(\mathbf{R N}=\mathbf{C R}^{\prime}\right)_{3}\right]_{n}$ complexes
}

\author{
Hassan Rabaâ, ${ }^{, \dagger}$ Mohammad A. Omary, ${ }^{\ddagger}$ Stefan Taubert, " and Dage \\ Sundholm $*$, \\ $\dagger$ †épartement de Chimie, ESCTM, University Ibn Tofail, P.O.B 133, 14000 Kenitra, \\ Morocco \\ $\ddagger$ Department of Chemistry, University of North Texas, Denton, TX 76203-5070, USA \\ \Department of Chemistry, P.O. Box 55 (A. I. Virtanens plats 1), FI-00014 University of \\ Helsinki, Finland \\ E-mail: hrabaa@yahoo.com; sundholm@chem.helsinki.fi
}

\begin{abstract}
The molecular structure of stacked cyclic trinuclear gold(I) complexes $\left[\mathrm{Au}_{3}\left(\mathrm{RN}=\mathrm{CR}^{\prime}\right)_{3}\right]_{n}$, with $n=1-4$, where $\mathrm{R}=\mathrm{H}$, methyl (Me), cyclopentyl $\left({ }^{c} \mathrm{Pe}\right)$, phenyl $(\mathrm{Ph})$, and $\mathrm{R}^{\prime}=\mathrm{OH}$, and methoxy (OMe) have been studied computationally at the second-order MøllerPlesset (MP2) and density functional theory (DFT) levels of theory. At the DFT level, the aurophilic and dispersion interactions were accounted for by using the TPSS functional in combination with the semi-empirical D3 correction. The structure optimizations yielded the lowest energy for a slided stacked structure of the $\left[\mathrm{Au}_{3}(\mathrm{HN}=\mathrm{COH})_{3}\right]_{2}$ dimer, where monomers are slightly shifted relative to one another. At the MP2 level, the slided structure is $32 \mathrm{~kJ} / \mathrm{mol}$ more stable than the staggered dimer structure, which
\end{abstract}


in turn is energetically $11 \mathrm{~kJ} / \mathrm{mol}$ below the eclipsed structure. The calculations show that aromatic ligands lead to a planar and prismatic structure of $\left[\mathrm{Au}_{3}(\mathrm{PhN}=\mathrm{COMe})_{3}\right]_{4}$, whereas for $\left[\mathrm{Au}_{3}\left({ }^{c} \mathrm{PeN}=\mathrm{COMe}\right)_{3}\right]_{4}$, a chair conformation is obtained due to steric effects. Excitation energies were calculated for $\left[\mathrm{Au}_{3}\left(\mathrm{RN}=\mathrm{CR}^{\prime}\right)_{3}\right]$ and $\left[\mathrm{Au}_{3}\left(\mathrm{RN}=\mathrm{CR}^{\prime}\right)_{3}\right]_{2}$ with $\mathrm{R}=\mathrm{H}, \mathrm{Me},{ }^{c} \mathrm{Pe}$ and $\mathrm{R}^{\prime}=\mathrm{OH}$ and $\mathrm{OMe}$ at the time-dependent density functional theory (TD-DFT) level using the optimized molecular structures of the singlet ground state. To simulate the luminescence spectra, the lowest triplet excitation energy was also calculated for the molecular structure of the lowest triplet state. The calculated excitation energies of $\left[\mathrm{Au}_{3}(\mathrm{HN}=\mathrm{COH})_{3}\right]$ and $\left[\mathrm{Au}_{3}(\mathrm{HN}=\mathrm{COH})_{3}\right]_{2}$ are compared with values obtained at the approximate singles and doubles coupled cluster (CC2) and the second-order algebraic diagrammatic construction $(\mathrm{ADC}(2))$ levels of theory. The calculated absorption and emission energies reproduce the experimental trends, with extremely large Stokes shifts. A solvoluminescence mechanism is also proposed.

Keywords: DFT, TD-DFT, MP2, CC2, ADC(2), semi-empirical dispersion correction, aurophilic interaction, ultraviolet-visible spectrum, absorption spectrum, phosphorescence, Stokes shift, solvoluminescence. 


\section{Introduction}

Solid-state materials consisting of cyclic trinuclear gold(I) complexes are known for their exceptional molecular structure and photophysical behavior that lead to a wide range of interesting and potentially useful chemical properties such as metallophilic bonding, metal-metal excimer bonding, and supramolecular assemblies. ${ }^{1-24}$ In the solid-state, the trinuclear gold(I) units form dimers, oligomers, or infinite molecular chains. ${ }^{16}$ Molecular materials consisting of the trinuclear gold(I) carbeniate complexes $\left[\mathrm{Au}_{3}\left(\mathrm{RN}=\mathrm{CR}^{\prime}\right)_{3}\right]_{n}$ belong to an interesting class of phosphorescent metal-organic compounds ${ }^{12,13,16}$ that may be used in a variety of electronic devices such as emitting layers for phosphorescent organic light-emitting diodes (PhOLEDs), down-conversion phosphors for inorganic LEDs, or as p-type semiconductors in organic thin film transistors (OTFTs). ${ }^{25}$

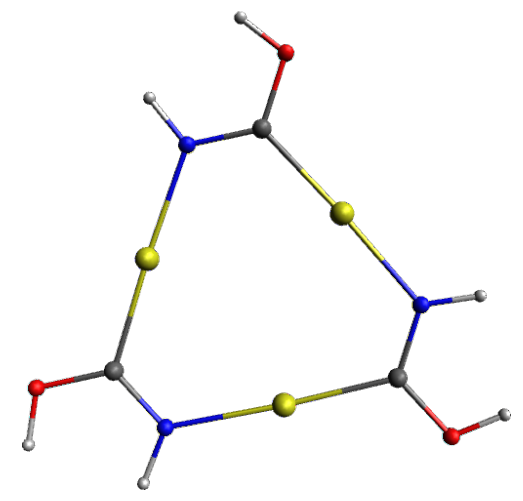

Figure 1: The molecular structure of the cyclic trinuclear gold(I) complex $\left[\mathrm{Au}_{3}(\mathrm{HN}=\mathrm{COH})_{3}\right]$ (1). Gold, nitrogen, carbon, oxygen and hydrogen atoms are shown in yellow, blue, gray, red and white, respectively.

The gold atoms of the individual $\left[\mathrm{Au}_{3}\left(\mathrm{RN}=\mathrm{CR}^{\prime}\right)_{3}\right]$ complexes $(\mathrm{R}=\mathrm{H}$, methyl $(\mathrm{Me})$, nbutyl ( $\left.{ }^{n} \mathrm{Bu}\right)$, cyclopentyl ( $\left.{ }^{c} \mathrm{Pe}\right)$, phenyl $(\mathrm{Ph})$, and $\mathrm{R}^{\prime}=\mathrm{OH}$, and methoxy (OMe) form an equilateral triangle and the gold(I) atoms are bridged by three rigid $\mathrm{RN}=\mathrm{CR}^{\prime}$ groups, as shown in Figure 1. In the solid state, the material consists of extended chains of the $\left[\mathrm{Au}_{3}\left(\mathrm{RN}=\mathrm{CR}^{\prime}\right)_{3}\right]$ complexes, which are assembled through strong intermolecular aurophilic $\mathrm{Au}-\mathrm{Au}$ interactions of 20-50 kJ/mol. ${ }^{1,3,26,27}$ Solid-state materials of $\left[\mathrm{Au}_{3}\left(\mathrm{RN}=\mathrm{CR}^{\prime}\right)_{3}\right]$ complexes with different structures have been synthesized. ${ }^{14,16}$ The crystalline polymorphic forms include the 
eclipsed (hexagonal prismatic), staggered (triclinic), staggered chair, stair-step, and slided conformations as shown in Figures 2a-2e. The experimental values for the intermolecular and intramolecular $\mathrm{Au}-\mathrm{Au}$ distances in molecular materials consisting of $\left[\mathrm{Au}_{3}\left(\mathrm{RN}=\mathrm{CR}^{\prime}\right)_{3}\right]$ complexes with different substituents $\left(\mathrm{R} / \mathrm{R}^{\prime}\right)$ are summarized in Table 1 . The intermolecular $\mathrm{Au}-\mathrm{Au}$ distances are in the range of $3.220 \AA$ to $3.675 \AA$, similar to the range of the intramolecular $\mathrm{Au}-\mathrm{Au}$ distances that are in the range of 3.266-3.339 $\AA$ in the trinuclear units. Some of the solid-state structures are irregular with large differences in the intermolecular $\mathrm{Au}-\mathrm{Au}$ distances, which may be a reason for the observed optical properties of these materials. ${ }^{16}$

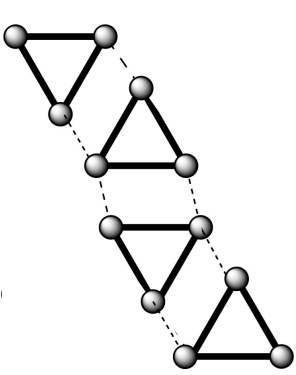

(a)

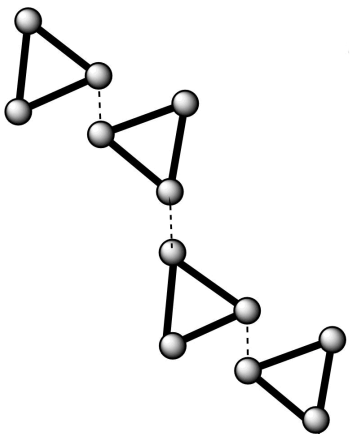

(b)

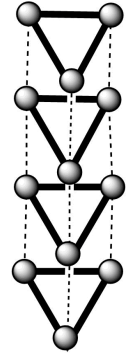

(c)

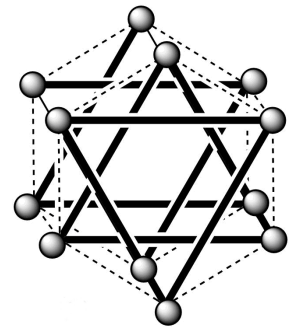

(d)

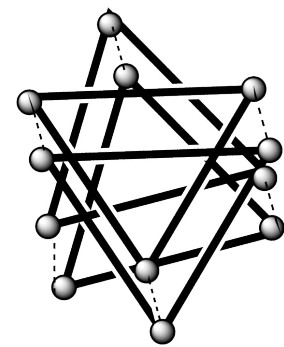

(e)

Figure 2: The different stacking structures of the $\left[\mathrm{Au}_{3}\left(\mathrm{RN}=\mathrm{CR}^{\prime}\right)_{3}\right]$ solid-state materials. (a) chair, (b) stair-step, (c) eclipsed, (d) staggered, and (e) slided structures. The intramolecular $\mathrm{Au}-\mathrm{Au}$ bonds are shown with solid lines and the intermolecular $\mathrm{Au}-\mathrm{Au}$ distances are indicated with dashed lines.

McDougald and coworkers have recently synthesized a number of trinuclear gold(I) complexes with structural and optical properties that depend on the bulkiness of n-butyl $\left({ }^{n} \mathrm{Bu}\right)$ and cyclopentyl ( $\left.{ }^{c} \mathrm{Pe}\right)$ substituents. ${ }^{16}$ The conformations of the four basic solid-state structures are sketched in Figure 2. The slided structure shown in Figure 2e was discovered computationally in this work. It is a novel conformation for this kind of solid-state materials that can though be identified by carefully scrutinizing the X-ray structure of the gold complexes forming helical stacks. ${ }^{28}$ In the $\left[\mathrm{Au}_{3}\left({ }^{c} \mathrm{PeN}=\mathrm{COMe}\right)_{3}\right]$ material, the molecular stacking is of type (a), where the monomers are assembled in the chair conformation leading 
to two intermolecular $\mathrm{Au}-\mathrm{Au}$ distances of $3.466 \AA$, whereas in the $\left[\mathrm{Au}_{3}\left({ }^{n} \mathrm{BuN}=\mathrm{COMe}\right)_{3}\right]$ and $\left[\mathrm{Au}_{3}\left({ }^{n} \mathrm{BuN}=\mathrm{CO}^{n} \mathrm{Bu}\right)_{3}\right]$ solids, the stacking is of type (b) with the trinuclear gold(I) units connected through a stair-step structure with the shortest intermolecular linked by two $\mathrm{Au}-\mathrm{Au}$ distances of $3.517 \AA$ and $3.435 \AA$, respectively. The individual molecules in the eclipsed ordered stack of $\left[\mathrm{Au}_{3}(\mathrm{MeN}=\mathrm{COMe})_{3}\right]$ and in the $\left[\mathrm{Au}_{3}\left(\mathrm{MeN}=\mathrm{CO}^{n} \mathrm{Bu}\right)_{3}\right]$ material have a stacking of type (c) with three short $\mathrm{Au}-\mathrm{Au}$ distances of $3.346 \AA$ each in the former and $3.437 \AA, 3.481 \AA$ and $3.484 \AA$ in the latter. In the $\left[\mathrm{Au}_{3}\left(\mathrm{MeN}=\mathrm{CO}^{n} \mathrm{Bu}\right)_{3}\right]$ material, the individual molecules aggregate with alternating direction of the $\mathrm{RN}=\mathrm{CR}^{\prime}\left(\mathrm{R}^{\prime} \mathrm{C}=\mathrm{NR}\right)$ bridges. The disordered stack of the hexagonal polymorph of $\left[\mathrm{Au}_{3}(\mathrm{MeN}=\mathrm{COMe})_{3}\right]$ exhibits the staggered stacking shown in Figure 2d.

Table 1: The experimental $\mathrm{Au}-\mathrm{Au}$ distances (in $\AA$ ) for $\left[\mathrm{Au}_{3}\left(\mathrm{RN}=\mathrm{CR}^{\prime}\right)_{3}\right]_{n}$ complexes that exhibit intertrimer distances within $3.8 \AA$. Average values are given for polymorphs exhibiting large variability. The abbreviations are $\mathrm{Me}=$ methyl, ${ }^{n} \mathrm{Bu}=\mathrm{n}$-butyl, ${ }^{n} \mathrm{Pe}=\mathrm{n}$-pentyl and ${ }^{c} \mathrm{Pe}=$ cyclopentyl. ${ }^{i}$ denotes Ref. 14 and ${ }^{i i}$ is from Ref. 16.

\begin{tabular}{llcc}
\hline \hline Compound & Structure & Intermolecular & Intramolecular \\
\hline $\mathrm{Me} / \mathrm{OMe}^{i}$ & Eclipsed (Hexagonal, ordered stack) & 3.346 & 3.308 \\
& Staggered (Hexagonal, disordered stack) & 3.384 & 3.280 \\
& Chair/Stair-step (Triclinic) & $3.220 ; 3.528$ & 3.339 \\
& Eclipsed/Stair-step (Monoclinic) & $3.28(3) ; 3.48(3) ; 3.65(3)$ & $3.31(2)$ \\
& Stair-step (Orthorhombic) & 3.618 & $3.315 ; 3.260 ; 3.332$ \\
${ }^{n} \mathrm{Pe} / \mathrm{OMe}^{i}$ & $3.346 ; 3.461 ; 3.613$ & $3.307(22)$ \\
& Stair-step (Triclinic) & 3.466 & $3.269 ; 3.290 ; 3.321$ \\
${ }^{c} \mathrm{Pe} / \mathrm{OMe}^{i i}$ & Chair (Triclinic) & $3.437 ; 3.481 ; 3.484$ & $3.280 ; 3.292 ; 3.297$ \\
$\mathrm{Me} / \mathrm{O}^{n} \mathrm{Bu}^{i i}$ & Eclipsed (Monoclinic) & $3.435 ; 3.443$ & $3.291 ; 3.304 ; 3.292$ \\
${ }^{n} \mathrm{Bu} / \mathrm{O}^{n} \mathrm{Bu}^{i i}$ Stair-step (Triclinic) & $3.517 ; 3.675$ & $3.266 ; 3.322 ; 3.333$ \\
${ }^{n} \mathrm{Bu} / \mathrm{OMe}^{i i}$ & Stair-step (Monoclinic) & \\
\hline \hline
\end{tabular}

The absorption and emission spectra of the trinuclear gold(I) carbeniate complexes have been studied experimentally by the Balch and Omary groups. ${ }^{12,14}$ The $\left[\mathrm{Au}_{3}(\mathrm{RN}=\mathrm{COR})_{3}\right]$ compounds were found to absorb light in the ultraviolet (UV) region between c. 250-300 nm, attributed to $\mathrm{S}_{0} \rightarrow \mathrm{S}_{n}$ transitions and at c. 320-390 nm $\left(\mathrm{S}_{0}-\mathrm{T}_{n}\right)$, whereas one or two emission bands appear in the visible spectral region due to $T_{1} \rightarrow S_{0}$ and $T_{2} \rightarrow S_{0}$ phosphorescence with extremely large Stokes shifts that are known to originate from drastic reductions in the 
intermolecular $\mathrm{Au}-\mathrm{Au}$ distances in extended excimers as compared to the ground state. ${ }^{10,14,16}$ The Stokes shifts reported in this work are both the practical definition namely the energy difference between the $\mathrm{S}_{0} \rightarrow \mathrm{S}_{1}$ absorption and the $\mathrm{T}_{1} \rightarrow \mathrm{S}_{0}$ emission $\left(S_{0} \rightarrow \mathrm{S}_{1} \cdots \mathrm{T}_{1} \rightarrow \mathrm{S}_{0}\right)$ and the strict definition, which is energy difference between the $\mathrm{S}_{0} \rightarrow \mathrm{T}_{1}$ absorption and the $\mathrm{T}_{1} \rightarrow \mathrm{S}_{0}$ emission $\left(S_{0} \rightarrow \mathrm{T}_{1} \rightarrow \mathrm{S}_{0}\right)$. The former assumes that that the spin-allowed transitions dominate the absorption spectra with weaker contributions from spin-forbidden transitions, which have been observed in corrected luminescence excitation spectra. ${ }^{29,30}$ The gold complexes studied herein emit mainly from the lowest triplet state and in some cases also from the second lowest triplet state. ${ }^{14,16,31}$

In this work, we computationally model the molecular structures, the electronic structures and optical properties of monomers, dimers, trimers, and tetramers of $\left[\mathrm{Au}_{3}\left(\mathrm{RN}=\mathrm{CR}^{\prime}\right)_{3}\right]_{n}$ complexes representing building blocks of the infinite molecular stacks of the solid-state materials. The molecular structures of a number of $\left[\mathrm{Au}_{3}\left(\mathrm{RN}=\mathrm{CR}^{\prime}\right)_{3}\right]_{n}$ cluster complexes with $\mathrm{R}=\mathrm{H}, \mathrm{Me},{ }^{c} \mathrm{Pe}, \mathrm{Ph}$, and $\mathrm{R}^{\prime}=\mathrm{OH}$, OMe substituents have been constructed and studied at the density functional theory (DFT) and ab initio correlation levels of theory. Absorption and emission energies have been calculated at the time-dependent density functional theory (TD-DFT), the approximate singles and doubles coupled cluster (CC2), and the secondorder algebraic diagrammatic construction $(\mathrm{ADC}(2))$ levels of theory. The obtained Stokes shifts are compared with available experimental data.

The article is organized as follows: Computational methods are described in Section 2. The molecular structures of the monomers, dimers and larger oligomers are discussed in Sections 3-5. Calculated excitation energies of the monomers and dimers are compared with experimental data in Section 6. A mechanism for the intriguing solvoluminescence phenomenon is described in Section 7 and, finally, the main conclusions are summarized in Section 8 . 


\section{Computational details}

The molecular structures of the $\left[\mathrm{Au}_{3}\left(\mathrm{RN}=\mathrm{CR}^{\prime}\right)_{3}\right]_{n}(n=1-4)$ complexes with $\mathrm{R} / \mathrm{R}^{\prime}=\mathrm{H} / \mathrm{OH}$, $\mathrm{Me} / \mathrm{OMe},{ }^{c} \mathrm{Pe} / \mathrm{OMe}, \mathrm{Ph} / \mathrm{OH}, \mathrm{Ph} / \mathrm{OMe}$ have been fully optimized at the density functional theory (DFT) level. ${ }^{32}$ The TPSS functional combined with the D3 semi-empirical dispersion correction was employed in the structure optimization. ${ }^{33,34}$ The harmonic vibrational frequencies were calculated in order to assess whether the optimized TPSS-D3 structures are true minima on the potential energy surface. The molecular structures of the singlet ground state of the $\left[\mathrm{Au}_{3}(\mathrm{RN}=\mathrm{COH})_{3}\right]_{2}$ dimer were also optimized at the second-order Møller-Plesset perturbation theory (MP2) level using the resolution of the identity approximation to speed up the calculations. ${ }^{35-38}$ The Karlsruhe triple- $\zeta$ basis sets augmented with polarization functions (def2-TZVP) have been used in all calculations. ${ }^{36}$ The Stuttgart effective core potentials (ECP) were used for $\mathrm{Au}$ in order to describe scalar relativistic effects. ${ }^{39-41}$ The stacking energies have been corrected for basis set superposition errors (BSSE) by using counterpoise (CP) corrections. ${ }^{42}$ The Cartesian coordinates of the molecular structures are given as supporting information (SI). The few lowest excitation energies were calculated at the DFT level using the linear-response time-dependent density-functional theory (TD-DFT) approach ${ }^{43,44}$ with the B3LYP and the BHLYP functionals. ${ }^{45-48}$ Excitation energies were also calculated at the approximate second-order coupled-cluster (CC2) level ${ }^{38,49}$ and at the second-order algebraic diagrammatic construction $(\mathrm{ADC}(2))$ level $^{50}$ using the resolution of the identity to speed up the computations. ${ }^{51}$ In the calculations on the excited states, solvent effects were taken into account by using the continuum solvation model (COSMO) ${ }^{52,53}$ with the relative dielectric constant $\left(\epsilon_{r}\right)$ of 4.81 for chloroform $\left(\mathrm{CHCl}_{3}\right)$. All calculations have been performed with the Turbomole package version 7.0. ${ }^{54,55}$ Figure 2 was made using the ChemBioDraw program. ${ }^{56}$ The molecular structures in Figures 1, 3, and 5-8 are visualized using the Avogadro program. ${ }^{57,58}$ Figure 4 was made with Gnuplot. ${ }^{59}$ The density differences in Figure 9 were plotted using gOpenMol version 3.0. ${ }^{60,61}$ 


\section{Molecular structure of $\left[\mathrm{Au}_{3}\left(\mathrm{RN}=\mathrm{CR}^{\prime}\right)_{3}\right]$}

The trinuclear gold(I) complexes consist of three gold atoms that form an equilateral triangle, whose sides consist of bridging $\mathrm{RN}=\mathrm{CR}^{\prime}$ groups. The intramolecular distances in the individual $\left[\mathrm{Au}_{3}\left(\mathrm{RN}=\mathrm{CR}^{\prime}\right)_{3}\right]$ moieties $(\mathbf{1})$ shown in Figure 1 are not very sensitive to the number of monomers in the stacks. The Cartesian coordinates of the molecular structures optimized at the TPSS-D3/def2-TZVP and MP2/def2-TZVP levels of theory are given as Supporting Information. Comparisons of the bond distances of the molecular ring show that the bond lengths calculated at the TPSS-D3 and MP2 levels agree well. The calculated bond distances are compared to experimental data in Table 2.

Table 2: Bond lengths (in $\AA$ ) of the $\left[\mathrm{Au}_{3}(\mathrm{HN}=\mathrm{COH})_{3}\right]$ ring calculated at the MP2 and TPSS-D3 levels are compared to experimental data for $\mathrm{Au}_{3}(\mathrm{MeN}=\mathrm{COMe})_{3}$.

\begin{tabular}{lccc}
\hline \hline & MP2 & TPSS-D3 & Exp. $^{8}$ \\
\hline $\mathrm{Au}-\mathrm{Au}$ & 3.350 & 3.421 & 3.308 \\
$\mathrm{Au}-\mathrm{N}$ & 2.020 & 2.064 & 2.030 \\
$\mathrm{Au}-\mathrm{C}$ & 1.943 & 1.995 & 2.000 \\
$\mathrm{C}-\mathrm{N}$ & 1.303 & 1.308 & 1.381 \\
$\mathrm{C}-\mathrm{O}$ & 1.346 & 1.355 & 1.361 \\
\hline \hline
\end{tabular}

The intramolecular $\mathrm{Au}-\mathrm{Au}$ distance in $\left[\mathrm{Au}_{3}(\mathrm{HN}=\mathrm{COH})_{3}\right]$ is $3.421 \AA$ at the TPSS-D3 level and $3.350 \AA$ at the MP2 level. The molecular structure of $\left[\mathrm{Au}_{3}(\mathrm{HN}=\mathrm{COH})_{3}\right]$ has not been determined experimentally. $\left[\mathrm{Au}_{3}(\mathrm{HN}=\mathrm{COH})_{3}\right]$ is used here as reference point for steric and electronic factor variations of experimentally relevant $R / R^{\prime}$ combinations. The AuAu distances for $\left[\mathrm{Au}_{3}(\mathrm{HN}=\mathrm{COH})_{3}\right]$ calculated at the MP2 and TPSS-D3 levels are in good agreement with the experimental value of $3.308 \AA$ for $\left[\mathrm{Au}_{3}(\mathrm{MeN}=\mathrm{COMe})_{3}\right] \cdot{ }^{14,16}$

\section{Molecular structures of the $\left[\mathrm{Au}_{3}(\mathrm{HN}=\mathrm{COH})_{3}\right]_{2}$ dimer}

Optimization of the molecular structure of the $\left[\mathrm{Au}_{3}(\mathrm{HN}=\mathrm{COH})_{3}\right]_{2}$ dimer at the TPSSD3/def2-TZVP level of theory yielded the eclipsed (2), staggered (3) and slided (4) conform- 
ers shown in Figure 3. The $\mathrm{RN}=\mathrm{CR}^{\prime}$ moieties of the stacked complexes can have two different orientations with respect to each other. In the head-head $(h h)$ structure the $\mathrm{RC}=\mathrm{NR}^{\prime}$ moieties of the monomers are oriented in the same e.g., clockwise direction, whereas in the head-tail $(h t)$ structure the monomers are oriented in opposite directions leading to an alternating orientation of the individual molecules in the solid state. In the eclipsed $h h$ conformer (2), the two monomers are stacked on top of each other yielding a $C_{3 \mathrm{~h}}$ structure, whereas in the staggered $h h$ conformer $(3)$ of $S_{6}$ symmetry the molecules are $60^{\circ}$ rotated relatively to each other. The eclipsed and staggered structures were obtained by imposing the corresponding symmetry, whereas in the fully unconstrained optimization, a slided conformer (4) was obtained. The eclipsed structure (2) has three equivalent short intermolecular $\mathrm{Au}-\mathrm{Au}$ contacts of $3.376 \AA$, whereas the staggered conformation (3) has six equivalent but slightly longer intermolecular $\mathrm{Au}-\mathrm{Au}$ distances of $3.852 \AA$. The slided structure (4) has two shorter intermolecular $\mathrm{Au}-\mathrm{Au}$ distances of $3.579 \AA$ and $3.622 \AA$ and three longer ones of $3.730 \AA$, $3.731 \AA$ and $3.767 \AA$.

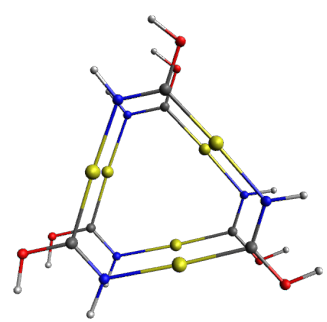

(a)

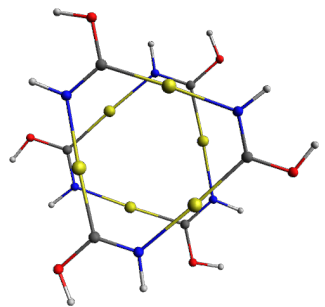

(b)

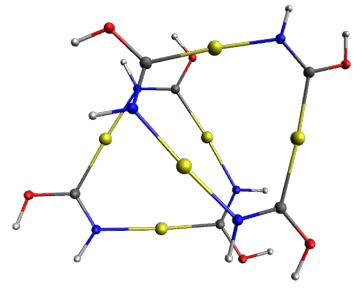

(c)

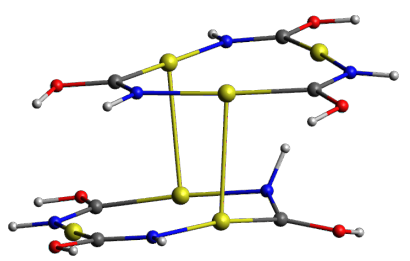

(d)

Figure 3: The molecular structures of the (a) eclipsed (2), (b) staggered (3), and (c) slided (4) conformers of $\left[\mathrm{Au}_{3}(\mathrm{HN}=\mathrm{COH})_{3}\right]_{2}$ optimized at the TPSS-D3/def2-TZVP level of theory. The molecular structure of the lowest triplet state of $\left[\mathrm{Au}_{3}(\mathrm{HN}=\mathrm{COH})_{3}\right]_{2}$ optimized at the TPSS-D3/TZVP level is shown in (d).

The BSSE corrected interaction energies are shown in Figure 4 as a function of the shortest intermolecular $\mathrm{Au}-\mathrm{Au}$ distance for the eclipsed (ECL), staggered (STA), and slided (SLD) conformers of $\left[\mathrm{Au}_{3}(\mathrm{HN}=\mathrm{COH})_{3}\right]_{2}$. The BSSE corrected interaction energies were calculated for fixed monomers of the ECL and STA structures as a function of the intermolecular distances along the symmetry axis. The interaction energy for the SLD structure was calculated 
for fixed monomers at selected distances along an axis through the center of mass defined by the positions of the Au atoms of the two trinuclear complexes.

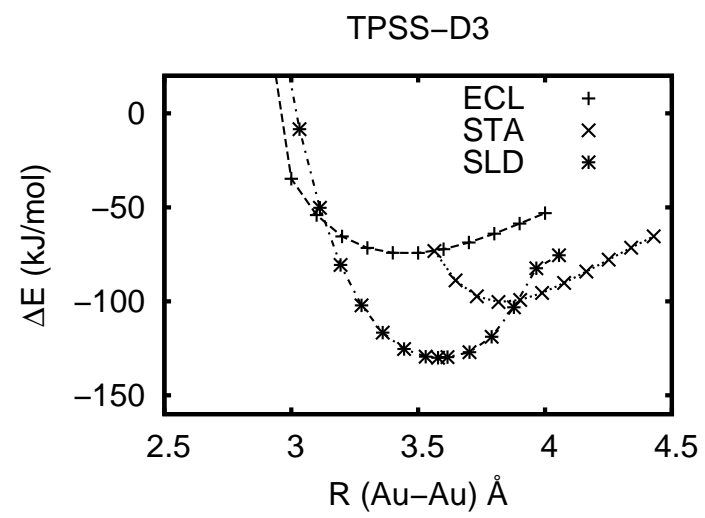

(a)

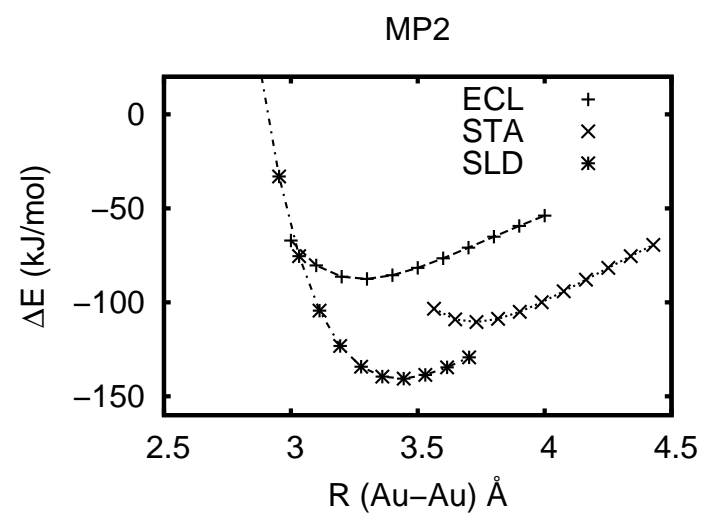

(b)

Figure 4: The potential energy curve for the eclipsed (ECL), staggered (STA), and slided (SLD) structures of $\left[\mathrm{Au}_{3}(\mathrm{HN}=\mathrm{COH})_{3}\right]_{2}$ calculated at (a) the TPSS-D3 and (b) the MP2 level as a function of the shortest $\mathrm{Au}-\mathrm{Au}$ distance.

The intermolecular $\mathrm{Au}-\mathrm{Au}$ distances corresponding to the energy minimum at the MP2 level are $3.3 \AA$ and $3.7 \AA$ for the ECL and STA structures. The corresponding distances calculated at the TPSS-D3 level are slightly longer or $3.4 \AA$ and $3.8 \AA$, respectively. For the SLD structure, the energy minimum obtained at the MP2 and TPSS-D3 levels is $3.4 \AA$ and $3.6 \AA$, respectively. The SLD structure is more stable than the ECL and STA ones. The TPSS-D3 binding energy of the ECL, STA, and SLD dimers in Figure $4 \mathrm{a}$ are $-74 \mathrm{~kJ} / \mathrm{mol}$, $-100 \mathrm{~kJ} / \mathrm{mol}$, and $-130 \mathrm{~kJ} / \mathrm{mol}$, respectively. The SLD structure is 30 (32) kJ/mol below the STA one, whereas the STA structure is $26(11) \mathrm{kJ} / \mathrm{mol}$ more stable than the ECL structure. The energy differences were calculated at TPSS-D3 level. The corresponding MP2 values are given in parenthesis. Counterpoise (CP) corrections of 7 (61) kJ/mol have been taken into account. The BSSE correction increases the $\mathrm{Au}-\mathrm{Au}$ distance by $0.2 \AA$ at the MP2 level. The D3 dispersion correction is essential for obtaining a binding interaction at the TPSS level. Electron correlation and the D3 correction consider not only aurophilic interactions between gold atoms but they also take van der Waals interaction between the rest of the molecules into account. van der Waals and electrostatic interactions between the organic 
moieties affect the stacking energies and the distances between the molecules in the stacks. Hydrogen bonds with the $\mathrm{OH}$ groups can also contribute to the interaction energy between the molecules in the stacks.

The potential energy curve for the rotation of the monomers from ECL $\left(0^{\circ}\right)$ to the STA $\left(60^{\circ}\right)$ structure is a barrierless decreasing function with an $26 \mathrm{~kJ} / \mathrm{mol}$ lower energy for the STA structure. The monomer structures were kept fixed with an intermolecular distance of $3.40 \AA$ resulting in a $\mathrm{Au}-\mathrm{Au}$ distance of $3.93 \AA$ for the $60^{\circ}$ rotated structure, which is slightly longer than the intermolecular $\mathrm{Au}-\mathrm{Au}$ distance of $3.85 \AA$ for the optimized STA structure.

\subsection{The triplet-state structure of $\left[\mathrm{Au}_{3}(\mathrm{HN}=\mathrm{COH})_{3}\right]_{2}$}

The molecular structure of the lowest triplet state of the $\left[\mathrm{Au}_{3}(\mathrm{HN}=\mathrm{COH})_{3}\right]_{2}$ dimer shown in Figure 3d was optimized at the TPSS-D3 level. The intermolecular Au-Au distances are shorter for the triplet state than for the singlet ground state with a shortest intermolecular $\mathrm{Au}-\mathrm{Au}$ distance of $2.860 \AA$ as compared to $3.579 \AA$ for the SLD structure of the singlet ground state. The triplet state has a SLD structure similar to the ground state and the monomers are less parallel relatively to each other than in the ground-state structure. The secondshortest intermolecular $\mathrm{Au}-\mathrm{Au}$ distance is $3.409 \AA$. The intramolecular $\mathrm{Au}-\mathrm{Au}$ distances of the trinuclear complexes are only $4-6 \mathrm{pm}$ shorter in the triplet state that in the singlet ground state. The more compact structure of the $\left[\mathrm{Au}_{3}(\mathrm{HN}=\mathrm{COH})_{3}\right]_{2}$ dimer in its triplet state has a considerable influence on the lowest excitation energies and thus on the Stokes shift as discussed in Section 6.

\section{Molecular structures of the $\left[\mathrm{Au}_{3}\left(\mathbf{R N}=\mathrm{CR}^{\prime}\right)_{3}\right]_{n}$ stacks}

The calculations on the stacks show that the intermolecular $\mathrm{Au}-\mathrm{Au}$ distances depend on the $\mathrm{R} / \mathrm{R}^{\prime}$ substituents and on the number of monomers in the stacks. In stacks with three or four $\left[\mathrm{Au}_{3}\left(\mathrm{RN}=\mathrm{CR}^{\prime}\right)_{3}\right]$ units, we obtained alternating intermolecular distances in the stacks. 
Dimer structures with shorter intramolecular $\mathrm{Au}-\mathrm{Au}$ contacts can be identified in the stacks with the other $\left[\mathrm{Au}_{3}\left(\mathrm{RN}=\mathrm{CR}^{\prime}\right)_{3}\right]$ units pushed slightly farther away. The intermolecular $\mathrm{Au}-\mathrm{Au}$ distances of the $\left[\mathrm{Au}_{3}\left(\mathrm{RN}=\mathrm{CR}^{\prime}\right)_{3}\right]_{n}$ stacks are given in Table 3 .

Table 3: The shortest intermolecular $\mathrm{Au}-\mathrm{Au}$ distances (in $\AA$ ) in the $\left[\mathrm{Au}_{3}(\mathrm{RN}=\mathrm{CR})_{3}\right]_{n}$ stacks as obtained in the optimizations at the TPSS-D3/def2-TZVP level.

\begin{tabular}{lccccc}
\hline \hline $\mathrm{R} / \mathrm{R}^{\prime}$ & Structure & $n=2$ & $n=3$ & $n=4$ & Exp. $^{14}$ \\
\hline $\mathrm{H} / \mathrm{OH}$ & $\mathrm{ECL}$ & 3.443 & & & \\
$\mathrm{H} / \mathrm{OH}$ & $\mathrm{STA}$ & 3.852 & & & \\
$\mathrm{H} / \mathrm{OH}$ & $\mathrm{SLD}$ & 3.533 & & & \\
$\mathrm{H} / \mathrm{OH}$ & & & $3.399,3.413$ & $3.171-3.349$ & \\
$\mathrm{Me} / \mathrm{OMe}$ & & $3.422-3.438$ & $3.157-3.556$ & $3.158-3.689$ & 3.220 \\
${ }^{c} \mathrm{Pe} / \mathrm{OMe}$ & & 4.160 & & $3.527-3.903$ & \multirow{2}{*}{3.466} \\
$\mathrm{Ph} / \mathrm{OH}$ & & & $3.390,3.409$ & $3.190,3.530,3.155$ & \\
$\mathrm{Ph} / \mathrm{OMe}$ & & & & \\
\hline \hline
\end{tabular}

\section{$5.1 \quad\left[\mathrm{Au}_{3}(\mathrm{HN}=\mathrm{COH})_{3}\right]_{n}(n=3-4)$}

The molecular structures of the $\left[\mathrm{Au}_{3}(\mathrm{HN}=\mathrm{COH})_{3}\right]$ trimer $(\mathbf{5})$ optimized at the TPSS-D3 level are shown in Figures 5c, 5d and 5e. For $\left[\mathrm{Au}_{3}(\mathrm{HN}=\mathrm{COH})_{3}\right]_{3}$, the hth orientation is the most stable structure with intermolecular $\mathrm{Au}-\mathrm{Au}$ distances ranging between $3.22 \AA$ and $3.42 \AA$. The $h h h$ stack is the least-stable structure lying $44 \mathrm{~kJ} / \mathrm{mol}$ above the $h$ th structure. The $h h t$ structure is $8.9 \mathrm{~kJ} / \mathrm{mol}$ above the $h t h$ one. Thus, the lowest energy is obtained for alternating head-tail structures. The relative energies of the dimers, trimers and tetramers with different head-tail orientations are given in Table 4.

The optimized structures of the $\left[\mathrm{Au}_{3}(\mathrm{HN}=\mathrm{COH})_{3}\right]_{4}$ tetramers $(6)$ are shown in Figures 5f-5i and the relative energies are given in Table 4. The individual complexes form a slided structure that has an alternating structure with one and two $\mathrm{Au}-\mathrm{Au}$ connections to the neighboring molecules as seen in Figure 6. The individual molecules are slightly tilted and slided leading to a helical stack with short $\mathrm{Au}-\mathrm{Au}$ distances of $3.35 \AA$ and $3.17 \AA$. The calculated structure is reminiscent of the recently reported experimental structure by Beltrán et 
al. ${ }^{28}$ where the trinuclear gold(I) complexes form helical columns that are mutually rotated by about $40^{\circ}$.

The stability of the head-head $(h h)$ and head-tail $(h t)$ configurations was assessed by optimizing several structures of the $\left[\mathrm{Au}_{3}(\mathrm{HN}=\mathrm{COH})_{3}\right]_{n}, n=2,3,4$ oligomers. The $h h$ and $h t$ of $\left[\mathrm{Au}_{3}(\mathrm{HN}=\mathrm{COH})_{3}\right]_{2}$; the $h h h$, hht, and $h t h$ structures of $\left[\mathrm{Au}_{3}(\mathrm{HN}=\mathrm{COH})_{3}\right]_{3}$ and the $h h h h, h h h t$, hhtt, and $h t h t$ structures of $\left[\mathrm{Au}_{3}(\mathrm{HN}=\mathrm{COH})_{3}\right]_{4}$ shown in Figure 5 were studied. The starting point for the optimizations was an eclipsed conformation and no symmetry constraints were imposed. The relative energies and shortest intermolecular $\mathrm{Au}-\mathrm{Au}$ distances in the optimized structures are listed in Table 4. The most stable conformations were found to be the ones with alternating head-tail structures, which is in disagreement with the conclusions that were drawn based on investigations of some crystal structures in the work by McDougald et al. ${ }^{16}$ The shortest intramolecular Au-Au distances are found for the head-tail pairs, and consequently the energetically most favorable trimer and tetramer conformations are the $h t h$ and $h t h t$ structures, respectively. The alternating stacking structures reduce the steric interaction and decrease the electrostatic repulsion between the monomers leading to shorter $\mathrm{Au}-\mathrm{Au}$ distances and stronger aurophilic interactions.

Table 4: Relative energies $\mathrm{E}_{\mathrm{rel}}$ (in $\mathrm{kJ} / \mathrm{mol}$ ) and the shortest $\mathrm{Au}-\mathrm{Au}$ distances $\mathrm{R}(\mathrm{Au}-\mathrm{Au}$ ) (in $\AA)$ for the different conformers of $\left[\mathrm{Au}_{3}(\mathrm{HN}=\mathrm{COH})_{3}\right]_{n}, n=2,3,4$.

\begin{tabular}{lllll}
\hline \hline Conformer & $\mathrm{E}_{\mathrm{rel}}$ & & $\mathrm{R}(\mathrm{Au}-\mathrm{Au})$ & \\
\hline$h h$ & 10.3 & 3.590 & & \\
$h t$ & 0.0 & 3.266 & 3.462 & \\
\hline$h h h$ & 44.2 & 3.527 & 3.269 & \\
$h h t$ & 8.9 & 3.558 & 3.247 & 3.551 \\
$h t h$ & 0.0 & 3.235 & 3.379 & 3.238 \\
\hline$h h h h$ & 32.1 & 3.541 & 3.552 & 3.553 \\
$h h h t$ & 11.1 & 3.545 & 3.190 & 3.253 \\
$h h t t$ & 11.9 & 3.553 & 3.197 & \\
$h t h t$ & 0.0 & 3.253 & & \\
\hline \hline
\end{tabular}




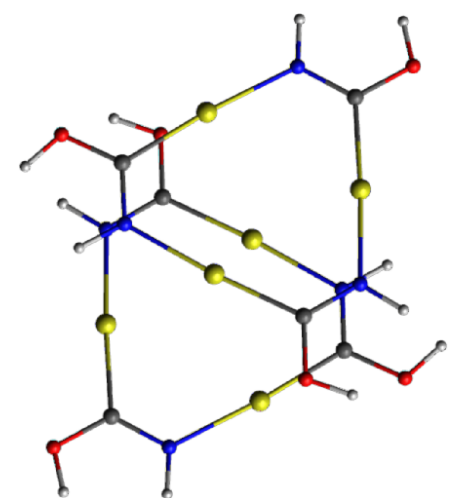

(a)

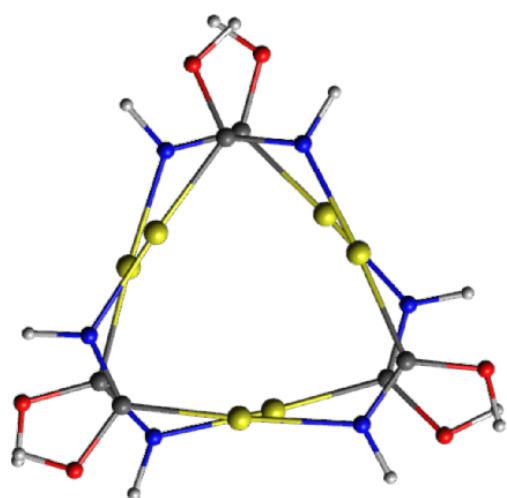

(b)

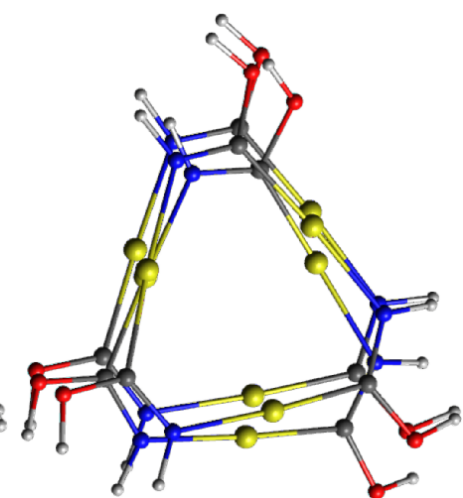

(c)

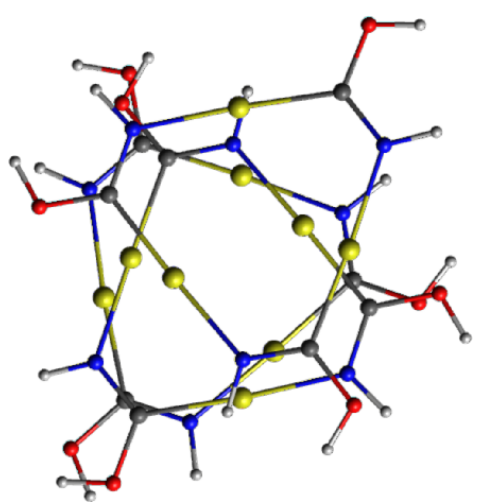

(d)

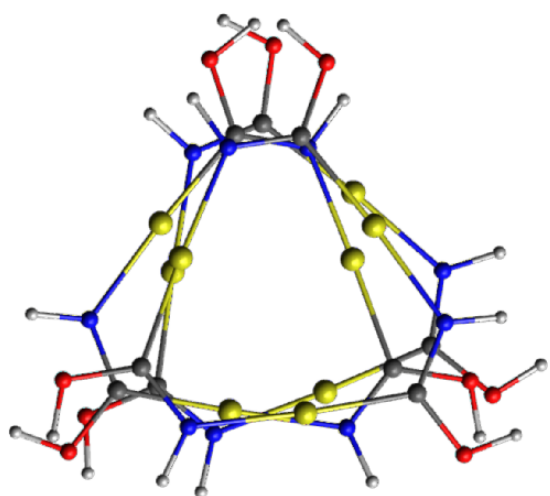

(e)

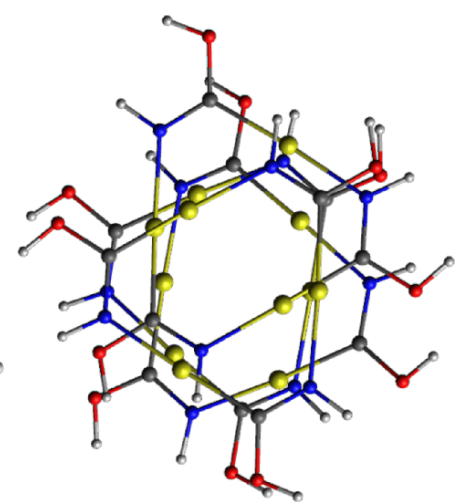

(f)

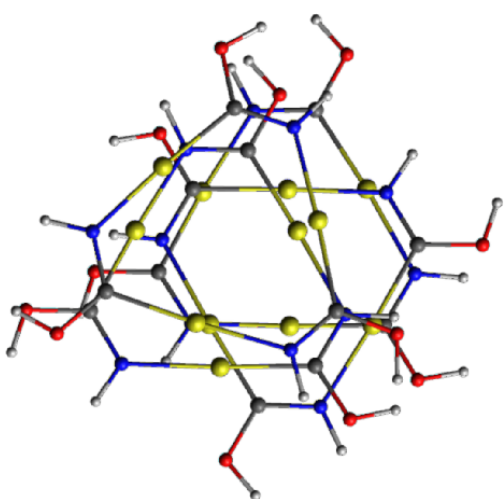

(g)

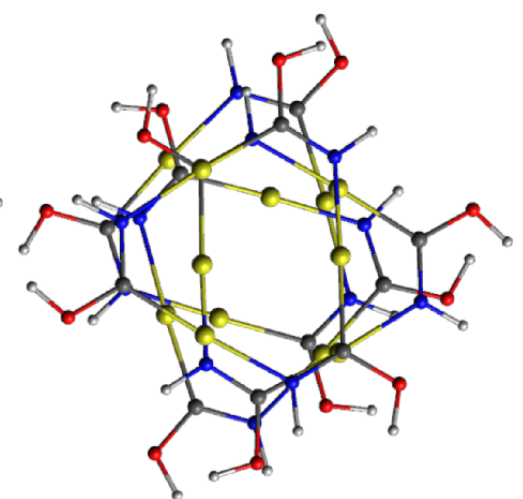

(h)

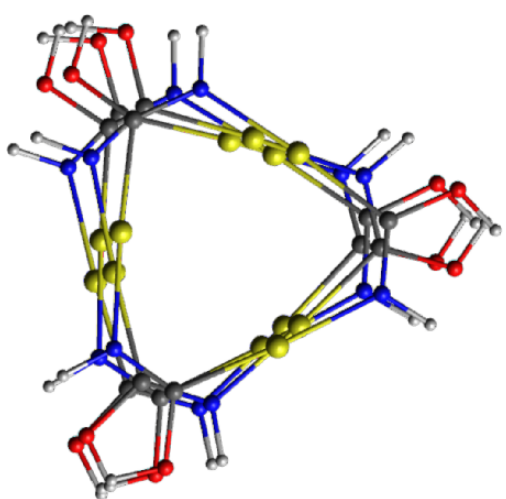

(i)

Figure 5: The optimized molecular structure of $\left[\mathrm{Au}_{3}(\mathrm{HN}=\mathrm{COH})_{3}\right]_{n}, n=2,3,4$ in the (a) $h h$, (b) $h t$, (c) $h h h$, (d) $h h t$, (e) $h t h$, (f) $h h h h$, (g) $h h h t$, (h) $h h t t$, and (i) $h t h t$ conformation. The structures were optimized at the TPSS-D3/def2-TZVP level. 


\section{$5.2\left[\mathrm{Au}_{3}(\mathrm{MeN}=\mathrm{COMe})_{3}\right]_{n}(n=2-4)$}

The structure of the $\left[\mathrm{Au}_{3}\left(\mathrm{MeN}=\mathrm{CR}^{\prime}\right)_{3}\right]$ solid-state materials with $\mathrm{R}^{\prime}=\mathrm{OMe}$ or $\mathrm{O}^{n} \mathrm{Bu}$ form trigonal prismatic structures with short intramolecular $\mathrm{Au}-\mathrm{Au}$ distances of $3.38 \AA$ and 3.43$3.48 \AA$, respectively. ${ }^{14,16}$ The prismatic $h h$ stacks were observed in only one of the four stacking motifs of the $\left[\mathrm{Au}_{3}(\mathrm{MeN}=\mathrm{COMe})_{3}\right]$ solids, whereas the $\left[\mathrm{Au}_{3}\left(\mathrm{MeN}=\mathrm{CO}^{n} \mathrm{Bu}\right)_{3}\right]$ solid exhibits alternating $(h t)$ stacks similar to the computationally-predicted one.

Molecular structure optimization at the TPSS-D3 level of the $\left[\mathrm{Au}_{3}(\mathrm{MeN}=\mathrm{COMe})_{3}\right]_{n}, n$ $=2,3,4$ stacks yielded similar geometries as observed experimentally. In the dimer $(\mathbf{7})$, the intermolecular $\mathrm{Au}-\mathrm{Au}$ bond distances range from $3.39 \AA$ to $3.44 \AA$, whereas shorter intermolecular $\mathrm{Au}-\mathrm{Au}$ distances of 3.16-3.35 $\AA$ were obtained for the trimer (8) and the tetramer (9). The stacks have two short and one long intermolecular $\mathrm{Au}-\mathrm{Au}$ contacts as in the experimentally observed chair-like conformation, which has intermolecular $\mathrm{Au}-\mathrm{Au}$ distances of $3.22 \AA$ to $3.52 \AA .{ }^{14}$ The optimized structure of the $\left[\mathrm{Au}_{3}(\mathrm{MeN}=\mathrm{COMe})_{3}\right]_{4}$ tetramer $(\mathbf{9})$ has a helical structure consisting of slided and tilted trinuclear complexes with short intermolecular $\mathrm{Au}-\mathrm{Au}$ distances of $3.18 \AA$, whereas in the solid state, the individual $\left[\mathrm{Au}_{3}(\mathrm{MeN}=\mathrm{COMe})_{3}\right]$ molecules are packed into symmetric trigonal prismatic ordered stacks (two-third) and staggered disordered stacks (one-third). ${ }^{14}$ Thus, the repulsion energy between the ligand groups is apparently smaller than the energy gain when packing the molecules into regular stacks in the solid state.

\section{$5.3\left[\mathrm{Au}_{3}\left({ }^{c} \mathrm{PeN}=\mathrm{COMe}\right)_{3}\right]_{n}$ and $\left[\mathrm{Au}_{3}(\mathrm{PhN}=\mathrm{COMe})_{3}\right]_{n}(n=2,4)$}

The spacings between the individual molecules of the $\left[\mathrm{Au}_{3}\left(\mathrm{RN}=\mathrm{CR}^{\prime}\right)_{3}\right]_{n}$ stacks are affected by the interactions between the $\mathrm{R}$ and $\mathrm{R}^{\prime}$ ligands on different molecules. The molecular structures for stacks of trinuclear gold(I) complexes with bulky ligands such as $\mathrm{R}={ }^{c} \mathrm{Pe}$ and $\mathrm{R}=$ $\mathrm{Ph}$ were optimized at the TPSS-D3 level. The $\left[\mathrm{Au}_{3}\left({ }^{c} \mathrm{PeN}=\mathrm{COMe}\right)_{3}\right]_{2}$ dimer $(\mathbf{1 0})$ has a slided structure with a long intermolecular $\mathrm{Au}-\mathrm{Au}$ distance of $4.437 \AA$. The $\left[\mathrm{Au}_{3}\left({ }^{\mathrm{c}} \mathrm{PeN}=\mathrm{COMe}\right)_{3}\right]_{4}$ tetramer (11) has one long and one short intermolecular $\mathrm{Au}-\mathrm{Au}$ distance of $4.302 \AA$ and 3.527 


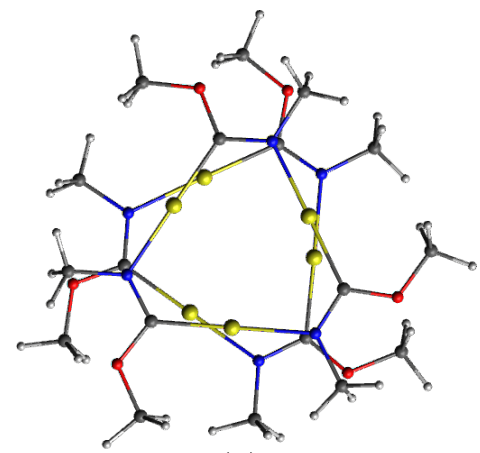

(a)

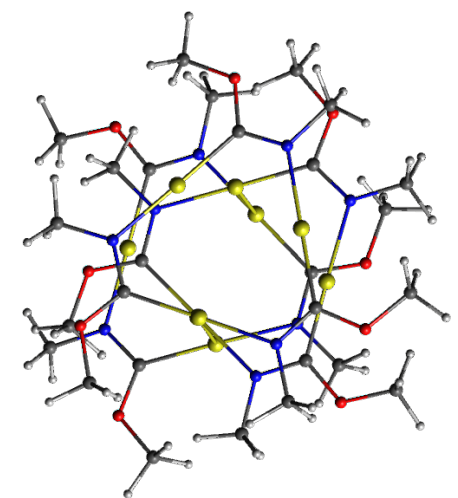

(b)

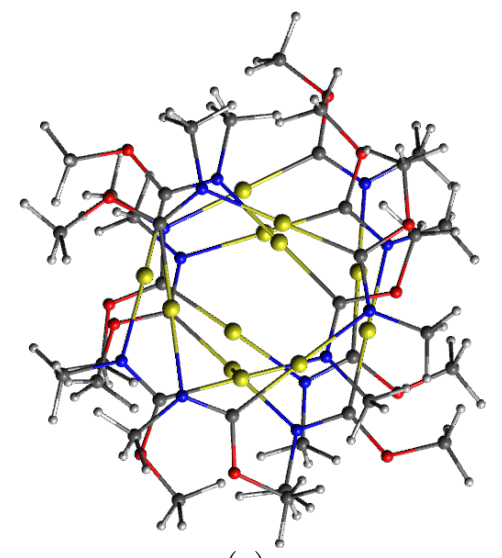

(c)

Figure 6: The molecular structures of (a) $\left[\mathrm{Au}_{3}(\mathrm{MeN}=\mathrm{COMe})_{3}\right]_{2} \quad$ (7), (b) $\left[\mathrm{Au}_{3}(\mathrm{MeN}=\mathrm{COMe})_{3}\right]_{3}(\mathbf{8})$, and $(\mathrm{c})\left[\mathrm{Au}_{3}(\mathrm{MeN}=\mathrm{COMe})_{3}\right]_{4}$ (9) optimized at the TPSSD3/def2-TZVP level.

$\AA$, respectively, which leads to the dimeric structure shown in Figure 7 . The calculations largely reproduce the experimental structures with alternating long and short intermolecular $\mathrm{Au}-\mathrm{Au}$ distances of $4.438 \AA$ and $3.466 \AA .{ }^{16} \mathrm{~A}$ similar solid-state structure is found for perfluoro-ortho-phenylene mercury compounds whose molecules form dimeric stacks with a staggered orientation of the individual molecules. ${ }^{62}$ Some of the nonplanar cyclopentyl $\left({ }^{c} \mathrm{Pe}\right)$ ligands can turn away from the molecular plane in the $\left[\mathrm{Au}_{3}\left({ }^{c} \mathrm{PeN}=\mathrm{COMe}\right)_{3}\right]_{n}$ stacks. In the $\left[\mathrm{Au}_{3}\left({ }^{c} \mathrm{PeN}=\mathrm{COMe}\right)_{3}\right]_{4}$ tetramer shown in Figure 7 , the two molecules in the middle of the tetramer stack form a dimer with the ${ }^{c}$ Pe groups turned outwards leading to a short intermolecular $\mathrm{Au}-\mathrm{Au}$ distance of $3.527 \AA$, whereas the outer $\left[\mathrm{Au}_{3}\left({ }^{c} \mathrm{PeN}=\mathrm{COMe}\right)_{3}\right]$ moieties with the ${ }^{c}$ Pe groups oriented inwards have a long intermolecular distance of $3.903 \AA$ to its neighboring molecule.

The planar phenyl ligands allow a closer stacking with $\pi-\pi$ interactions between the aromatic rings leading to the shortest intramolecular distance of $3.155 \AA$. Surprisingly, this distance is even shorter than that obtained for the $\left[\mathrm{Au}_{3}(\mathrm{HN}=\mathrm{COH})_{3}\right]_{2}$ dimer. Thus, the molecular structures of $\left[\mathrm{Au}_{3}(\mathrm{PhN}=\mathrm{COMe})_{3}\right]_{n}$ stacks shown in Figure 8 significantly differ from the structures obtained with $\mathrm{R}={ }^{c} \mathrm{Pe}$. The molecular structure of the $\left[\mathrm{Au}_{3}(\mathrm{PhN}=\mathrm{COMe})_{3}\right]_{2}$ dimer (12) shown in Figure 8a has a slided structure with a short intermolecular $\mathrm{Au}-\mathrm{Au}$ dis- 

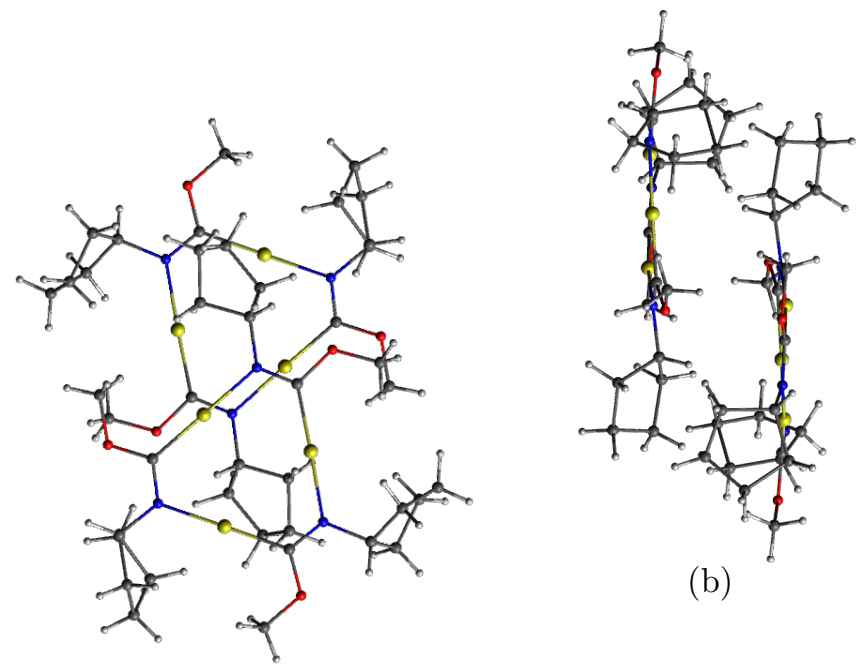

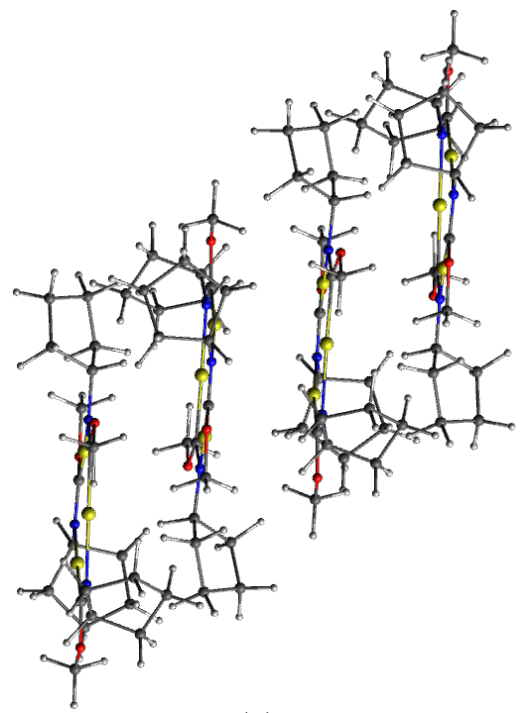

(c)

(a)

Figure 7: The molecular structure of the $\left[\mathrm{Au}_{3}\left({ }^{c} \mathrm{PeN}=\mathrm{COMe}\right)_{3}\right]_{2}$ dimer (10) (a) and (b) and of the $\left[\mathrm{Au}_{3}\left({ }^{c} \mathrm{PeN}=\mathrm{COMe}\right)_{3}\right]_{4}$ tetramer $(\mathbf{1 1})(\mathrm{c})$ optimized at the TPSS-D3/def2-TZVP level.

tance of $3.533 \AA$. The $\mathrm{Au}-\mathrm{Au}$ distance is slightly longer than the intermolecular distance because of the slided structure. Even though the phenyl ligand is bulky, a helical tetramer structure (13) is obtained with three short intermolecular $\mathrm{Au}-\mathrm{Au}$ distances of 3.249/3.308/3.284 $\AA$ as in $\left[\mathrm{Au}_{3}(\mathrm{MeN}=\mathrm{COMe})_{3}\right]_{n}$, because the $\pi-\pi$ interactions between the aromatic phenyl rings and the aurophilic interaction between the gold atoms pull the trinuclear gold(I) complexes close to each other. The molecular structure of the $\left[\mathrm{Au}_{3}(\mathrm{PhN}=\mathrm{COMe})_{3}\right]_{4}$ tetramer is shown in Figure 8b.

A helical stacking is obtained for complex (13), where a pronounced sliding is observed for stacks with $n \geq 3$. The sliding pattern of the stacking leads to strong aurophilic and other supramolecular interactions even for molecules with bulky ligands such as $\mathrm{Ph}$ and ${ }^{c} \mathrm{Pe}$. 


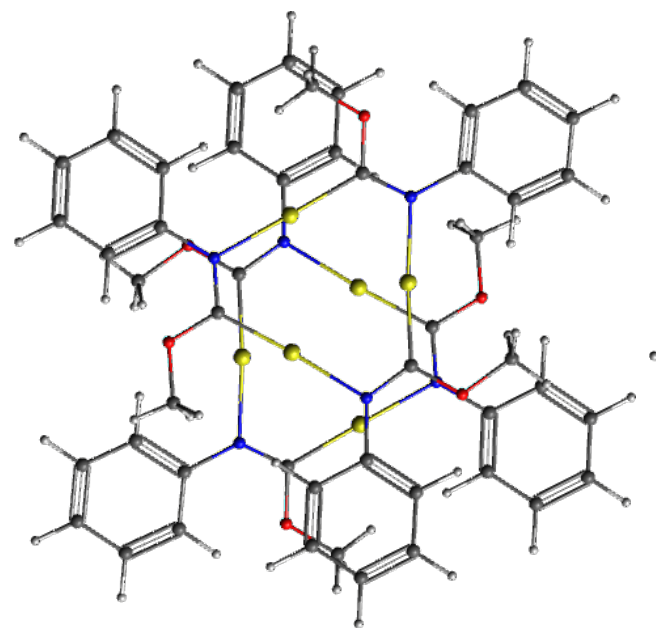

(a)

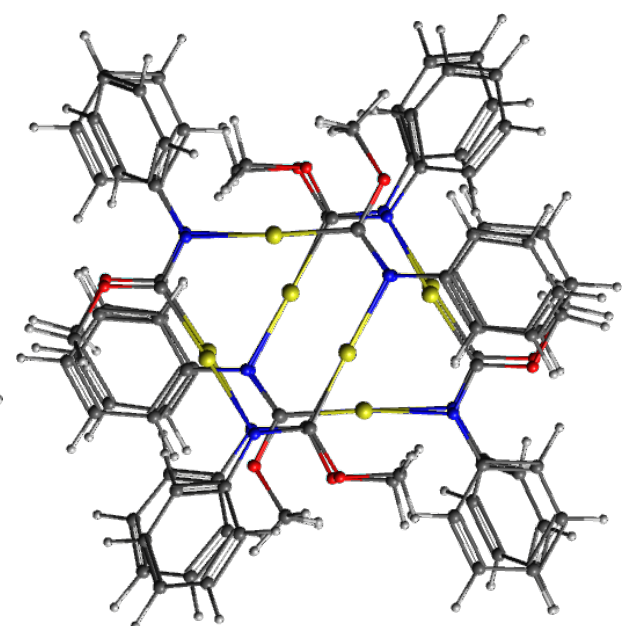

(b)

Figure 8: The molecular structure of (a) $\left[\mathrm{Au}_{3}(\mathrm{PhN}=\mathrm{COMe})_{3}\right]_{2} \quad$ (12) and (b) $\left[\mathrm{Au}_{3}(\mathrm{PhN}=\mathrm{COMe})_{3}\right]_{4}(\mathbf{1 3})$ optimized at the TPSS-D3/def2-TZVP level.

\section{Calculations of absorption and emission spectra}

The hexagonal, triclinic, and monoclinic solid-state structures of $\left[\mathrm{Au}_{3}(\mathrm{MeN}=\mathrm{COMe})_{3}\right]$ and other structures with various $\mathrm{R} / \mathrm{R}^{\prime}$ ligands have different experimental absorption and emission spectra. ${ }^{14,16}$ The hexagonal polymorph of $\left[\mathrm{Au}_{3}(\mathrm{MeN}=\mathrm{COMe})_{3}\right]$ has a broad absorption band between $240 \mathrm{~nm}$ and $420 \mathrm{~nm} .{ }^{14}$ It has a dual luminescence with a short-lived phosphorescence with the peak maximum at $446 \mathrm{~nm}$ and a broad longer-lived phosphorescence band whose maximum is at $552 \mathrm{~nm} .{ }^{8}$ The luminescence band with the peak maximum at $446 \mathrm{~nm}$ could originate from excitons that are mainly confined on the monomers of the $\left[\mathrm{Au}_{3}(\mathrm{MeN}=\mathrm{COMe})_{3}\right]$ molecules, since the $\left[\mathrm{Au}_{3}(\mathrm{MeN}=\mathrm{COMe})_{3}\right]$ complex in $\mathrm{CHCl}_{3}$ solution also emits light in that energy range (400-500 nm). However, a large red shift is observed for the solid-state excitation energy when monitoring the $446 \mathrm{~nm}$ emission band as compared to the absorption band of $\left[\mathrm{Au}_{3}(\mathrm{MeN}=\mathrm{COMe})_{3}\right]$ in the solution suggesting a different mechanism for the solid state. The prismatic infinite stacks of both $\left[\mathrm{Au}_{3}(\mathrm{MeN}=\mathrm{COMe})_{3}\right]$ and $\left[\mathrm{Au}_{3}\left(\mathrm{MeN}=\mathrm{CO}^{n} \mathrm{Bu}\right)_{3}\right]$ materials attain the blue emission at $446 \mathrm{~nm}$ due to a relatively small Stokes shift. ${ }^{16}$ The exciton leading to the yellow luminescence at $552 \mathrm{~nm}$ has most likely a significant electron density between the $\left[\mathrm{Au}_{3}(\mathrm{MeN}=\mathrm{COMe})_{3}\right]$ complexes as shown in the dimer 
model in Figure 9b. The hexagonal polymorph also displays yellow solvoluminescence. ${ }^{8,14,16}$

Solids with pronounced dimeric structures such as the $\left[\mathrm{Au}_{3}\left({ }^{c} \mathrm{PeN}=\mathrm{COMe}\right)_{3}\right]_{4}$ tetramer shown in Figure 7 also exhibit lower-energy emission in the yellow-red region with extremely large Stokes shifts. ${ }^{16}$ It is therefore reasonable to assign the yellow emission to self-trapped excitons in the dimers of the extended stacks. This assignment is also supported by the suggested mechanism of the solvoluminescence phenomenon in Section 7.

The absorption and emission spectra of the triclinic polymorph is similar to the one for the hexagonal polymorph in the UV region and in the blue part of the visible spectrum. However, the triclinic structure does not display any strong yellow luminescence. The photophysical and conducting properties of the triclinic and monoclinic polymorphs of $\left[\mathrm{Au}_{3}(\mathrm{MeN}=\mathrm{COMe})_{3}\right]$ are similar to those of $\left[\mathrm{Au}_{3}\left(\mathrm{MeN}=\mathrm{CO}^{n} \mathrm{Bu}\right)_{3}\right]$ and the ordered prismatic stacks of the hexagonal polymorph of $\left[\mathrm{Au}_{3}(\mathrm{MeN}=\mathrm{COMe})_{3}\right]$. They have blue emissions with relatively small Stokes shifts, whereas the yellow emission from the dimeric units of $\left[\mathrm{Au}_{3}\left({ }^{c} \mathrm{PeN}=\mathrm{COMe}\right)_{3}\right]_{2}$ and $\left[\mathrm{Au}_{3}(\mathrm{MeN}=\mathrm{COMe})_{3}\right]_{2}$ probably originates from self-trapped excitons. The monoclinic structure has a much narrower absorption band than the two other solid-state structures, with the absorption maximum at $350 \mathrm{~nm}$. The luminescence band of the monoclinic polymorph lies between $400 \mathrm{~nm}$ and $500 \mathrm{~nm} .{ }^{14}$

The absorption spectrum of the $\left[\mathrm{Au}_{3}(\mathrm{MeN}=\mathrm{COMe})_{3}\right]$ complex in $\mathrm{CHCl}_{3}$ solution has an intense absorption band between $230 \mathrm{~nm}$ and $300 \mathrm{~nm}$ with peak maxima at $250 \mathrm{~nm}, 265 \mathrm{~nm}$ and $285 \mathrm{~nm}$ and it emits light mainly between 400 and $450 \mathrm{~nm} .{ }^{9}$ Thus, the yellow luminescence with the peak maximum at $552 \mathrm{~nm}$ seems to be related to the sandwich structure of the hexagonal polymorph.

The absorption energies were calculated using the optimized molecular structures of the singlet ground state, whereas the phosphorescence energies were obtained by calculating the excitation energy of the first triplet state using the molecular structures optimized for the lowest triplet state. The lowest singlet-to-singlet excitation energy corresponds to the energetically lowest peak in the experimental absorption spectrum, whereas the transition from 
the lowest triplet state to the ground state can be assigned to the luminescence spectrum. Solvent effects were accounted for by using the COSMO continuum solvent model in the calculations.

Calculation of the electron-density difference between the $S_{0}$ and $S_{1}$ states using the molecular structure of the $\mathrm{S}_{0}$ state yields the electron and hole densities of the created exciton of the $\mathrm{S}_{0} \rightarrow \mathrm{S}_{1}$ excitation. Analogously, the electron-density difference between the $\mathrm{T}_{1}$ and $\mathrm{S}_{0}$ states using the molecular structure of the $\mathrm{T}_{1}$ state corresponds to the electron and hole densities of the annihilated exciton when the molecule emits a photon and returns to the ground state. ${ }^{64}$ The electron density (in red) and hole density (in blue) of the exciton for the $\left[\mathrm{Au}_{3}(\mathrm{MeN}=\mathrm{COMe})_{3}\right]_{2}$ dimer are shown in Figure 9. The density difference shows that the created exciton upon excitation is distributed over the two molecules of the dimer, whereas relaxation of the molecular structure of the $\mathrm{T}_{1}$ state affects the distribution of the exciton. For the $T_{1}$ structure, electron density of the $T_{1}$ state increases between the monomers pulling the molecules towards each other, which lowers the total energy of the dimer and the exciton energy leading to the extremely large Stokes shifts observed for the dimeric structures.

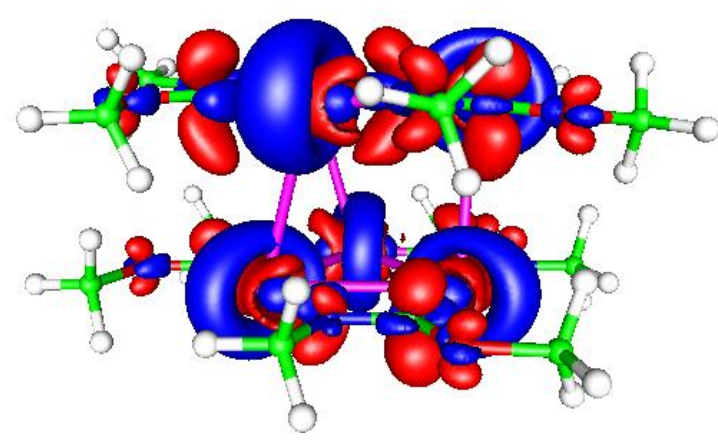

(a)

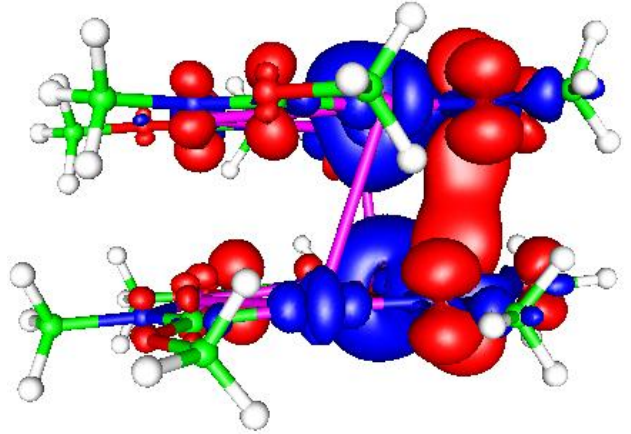

(b)

Figure 9: (a) The electron-density difference (exciton density) between the ground state and the lowest excited state singlet state for $\left[\mathrm{Au}_{3}(\mathrm{MeN}=\mathrm{COMe})_{3}\right]_{2}$ calculated at the B3LYP/def2TZVP level using the molecular structure of the ground state. (b) The electron-density difference between the ground state and the lowest excited triplet state of $\left[\mathrm{Au}_{3}(\mathrm{MeN}=\mathrm{COMe})_{3}\right]_{2}$ (7) calculated at the same level using the molecular structure of the triplet state. An isosurface value of 0.001 was used. 


\subsection{Absorption and emission energies of $\left[\mathrm{Au}_{3}\left(\mathrm{RN}=\mathrm{CR}^{\prime}\right)_{3}\right]$}

The absorption spectra of $\left[\mathrm{Au}_{3}\left(\mathrm{RN}=\mathrm{CR}^{\prime}\right)_{3}\right]$, with $\mathrm{R}=\mathrm{H}, \mathrm{Me},{ }^{c} \mathrm{Pe}$ and $\mathrm{R}^{\prime}=\mathrm{OH}$, OMe have been calculated at the TD-DFT level using the B3LYP and BHLYP functionals. The BHLYP functional with $50 \%$ Hartree-Fock exchange has been employed in order to check whether calculations at the B3LYP level suffer from spurious charge transfer problems. The obtained absorption and emission energies and wavelengths as well as the corresponding Stokes shifts for the monomers are summarized in Table 5 .

Table 5: The transition energies (in $\mathrm{eV}$ ) and the corresponding wavelengths (in $\mathrm{nm}$ ) for the absorption $\left(\mathrm{S}_{0} \rightarrow \mathrm{S}_{1}\right)$ and emission $\left(\mathrm{T}_{1} \rightarrow \mathrm{S}_{0}\right)$ processes of the $\left[\mathrm{Au}_{3}\left(\mathrm{RN}=\mathrm{CR}^{\prime}\right)_{3}\right]$ monomers are reported. The $S_{0} \rightarrow \mathrm{S}_{1} \cdots \mathrm{T}_{1} \rightarrow \mathrm{S}_{0}$ Stokes shifts (in eV) are also reported. The excitation energies have been calculated at the B3LYP and BHLYP levels using the def2-TZVP basis set.

\begin{tabular}{llccccc}
\hline \hline $\mathrm{R} / \mathrm{R}^{\prime}$ & Level & $\begin{array}{c}\mathrm{S}_{0} \rightarrow \mathrm{S}_{1} \\
\mathrm{eV}\end{array}$ & $\begin{array}{c}\mathrm{T}_{1} \rightarrow \mathrm{S}_{0} \\
\mathrm{eV}\end{array}$ & $\begin{array}{c}\mathrm{S}_{0} \rightarrow \mathrm{S}_{1} \\
\mathrm{~nm}\end{array}$ & $\begin{array}{c}\mathrm{T}_{1} \rightarrow \mathrm{S}_{0} \\
\mathrm{~nm}\end{array}$ & $\begin{array}{c}\text { Stokes shift } \\
\mathrm{eV}\end{array}$ \\
\hline $\mathrm{H} / \mathrm{OH}$ & B3LYP & 4.733 & 1.334 & 262 & 929 & 3.339 \\
$\mathrm{H} / \mathrm{OH}$ & BHLYP & 5.416 & 1.477 & 229 & 839 & 3.939 \\
$\mathrm{Me} / \mathrm{OMe}$ & B3LYP & 4.654 & 1.044 & 266 & 1188 & 3.610 \\
$\mathrm{Me} / \mathrm{OMe}$ & BHLYP & - & 1.395 & - & 889 & - \\
${ }^{c} \mathrm{Pe} / \mathrm{OMe}$ & B3LYP & 4.686 & 1.019 & 265 & 1216 & 3.667 \\
${ }^{c} \mathrm{Pe} / \mathrm{OMe}$ & BHLYP & 5.249 & 1.352 & 236 & 917 & 3.897 \\
\hline \hline
\end{tabular}

The calculations show that there are rather small differences between the absorption energies for the three molecules. The $\mathrm{S}_{0} \rightarrow \mathrm{S}_{1}$ absorption energies calculated at the BHLYP are 0.6-0.7 eV higher than obtained at the B3LYP level. The absorption energy for $\left[\mathrm{Au}_{3}(\mathrm{MeN}=\mathrm{COMe})_{3}\right]$ could not be obtained at the BHLYP level, because the Kohn-Sham reference state was not stable. ${ }^{63}$ The calculations yielded large $\mathrm{S}_{0} \rightarrow \mathrm{S}_{1} \cdots \mathrm{T}_{1} \rightarrow \mathrm{S}_{0}$ Stokes shift of 3.3-3.9 eV. The emission energies and Stokes shifts are larger at the BHLYP level than obtained in the B3LYP calculations. The B3LYP emission energy of $\left[\mathrm{Au}_{3}(\mathrm{HN}=\mathrm{COH})_{3}\right]$ is higher than for the two other molecules and its Stokes shift is smaller suggesting that the excitation process to some extent also involves the substituents. The B3LYP and BHLYP calculations yielded qualitatively concordant results, even though the BHLYP energies are 
systematically larger than obtained at the B3LYP level.

\subsection{Absorption and emission energies of $\left[\mathrm{Au}_{3}\left(\mathbf{R N}=\mathbf{C R}^{\prime}\right)_{3}\right]_{2}$}

The absorption and emission energies of the $\left[\mathrm{Au}_{3}\left(\mathrm{RN}=\mathrm{CR}^{\prime}\right)_{3}\right]_{2}$ dimers, with $\mathrm{R}=\mathrm{Me},{ }^{c} \mathrm{Pe}$ and $\mathrm{R}^{\prime}=$ OMe calculated at the B3LYP and BHLYP levels are summarized in Table 6 . The absorption and emission energies for the $\left[\mathrm{Au}_{3}(\mathrm{HN}=\mathrm{COH})_{3}\right]_{2}$ dimer calculated at the DFT levels are also compared with excitation energies calculated at the ab initio correlated $\mathrm{ADC}(2)$ and $\mathrm{CC} 2$ levels of theory.

The absorption energies of $\left[\mathrm{Au}_{3}(\mathrm{HN}=\mathrm{COH})_{3}\right]_{2}$ and $\left[\mathrm{Au}_{3}(\mathrm{MeN}=\mathrm{COMe})_{3}\right]_{2}$ are about 0.5 eV red shifted as compared the lowest singlet excitation energy of the corresponding monomers, whereas $\left[\mathrm{Au}_{3}\left({ }^{c} \mathrm{Pe}=\mathrm{COMe}\right)_{3}\right]$ and its dimer have almost the same excitation energies at the DFT level. Calculations on the dimers at the B3LYP/COSMO and BHLYP/COSMO levels yielded almost the same excitation energies as obtained in the gas-phase calculation. The calculated emission energy of the $\left[\mathrm{Au}_{3}(\mathrm{HN}=\mathrm{COH})_{3}\right]_{2}$ dimer is almost unaffected by the use of COSMO, whereas COSMO blue shifts the emission energy of $\left[\mathrm{Au}_{3}\left({ }^{c} \mathrm{Pe}=\mathrm{COMe}\right)_{3}\right]_{2}$ by $1 \mathrm{eV}$ at the B3LYP level and by $0.6 \mathrm{eV}$ at the BHLYP level, indicating that the dimers with larger substituents suffer from spurious charge transfer problems at the DFT levels. The emission energies for $\left[\mathrm{Au}_{3}(\mathrm{MeN}=\mathrm{COMe})_{3}\right]_{2}$ is about $1 \mathrm{eV}$ higher than for $\left[\mathrm{Au}_{3}(\mathrm{HN}=\mathrm{COH})_{3}\right]_{2}$ suggesting that the emission energy depends more strongly on the molecular structure than the absorption energy. The emission energy for the $h t$ structure of $\left[\mathrm{Au}_{3}(\mathrm{HN}=\mathrm{COH})_{3}\right]_{2}$ is about the same as for $\left[\mathrm{Au}_{3}(\mathrm{MeN}=\mathrm{COMe})_{3}\right]_{2}$ and almost $1 \mathrm{eV}$ higher than for the $h h$ structure of $\left[\mathrm{Au}_{3}(\mathrm{HN}=\mathrm{COH})_{3}\right]_{2}$. The significantly different emission energies for the $h h$ and $h t$ structures also lead to a much smaller Stokes shifts for the dimer with $h t$ orientation of the monomers. The charge transfer problems of the $\left[\mathrm{Au}_{3}\left({ }^{c} \mathrm{Pe}=\mathrm{COMe}\right)_{3}\right]_{2}$ dimer results in much larger Stokes shifts than for the other dimers. The calculations show that the emission wave length of the dimers are expected to be in the range of 500-600 nm, which agrees well with experimental data for the solid-state material. For the $\left[\mathrm{Au}_{3}\left({ }^{c} \mathrm{Pe}=\mathrm{COMe}\right)_{3}\right]$ solid, the maximum of the ab- 
Table 6: The transition energies (in eV) and wavelengths (in $\mathrm{nm}$ ) for the $\mathrm{S}_{0} \rightarrow \mathrm{S}_{1}$ and $\mathrm{S}_{0} \rightarrow \mathrm{T}_{1}$ absorption processes and for the $\mathrm{T}_{1} \rightarrow \mathrm{S}_{0}$ emission process of the $\left[\mathrm{Au}_{3}\left(\mathrm{RN}=\mathrm{CR}^{\prime}\right)_{3}\right]_{2}$ dimers are listed. The Stokes shifts (in eV) for the $\mathrm{S}_{0} \rightarrow \mathrm{S}_{1} \cdots \mathrm{T}_{1} \rightarrow \mathrm{S}_{0}$ and $\mathrm{S}_{0} \rightarrow \mathrm{T}_{1} \rightarrow \mathrm{S}_{0}$ absorptionemission processes are also reported. The excitation energies have been calculated at the B3LYP, BHLYP, ADC(2) and CC2 levels of theory using the def2-TZVP basis set. In the COSMO calculations, an $\epsilon_{r}$ of 4.81 corresponding to $\mathrm{CHCl}_{3}$ was used.

\begin{tabular}{|c|c|c|c|c|c|c|}
\hline 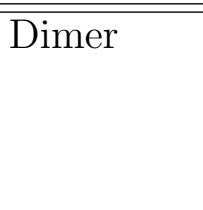 & $\overline{\text { Method }}$ & $\begin{array}{c}\mathrm{S}_{0} \rightarrow \mathrm{S}_{1} \\
\mathrm{eV} \\
(\mathrm{nm})\end{array}$ & $\begin{array}{c}\mathrm{eV} \\
(\mathrm{nm})\end{array}$ & \begin{tabular}{c}
\multicolumn{2}{c}{ Stokes shift } \\
$\mathrm{S}_{0} \rightarrow \mathrm{S}_{1} \cdots \mathrm{T}_{1} \rightarrow \mathrm{S}_{0}$ \\
$\mathrm{eV}$
\end{tabular} & $\begin{array}{c}\mathrm{S}_{0} \rightarrow \mathrm{T}_{1} \\
\mathrm{eV} \\
(\mathrm{nm})\end{array}$ & $\begin{array}{c}\text { Stokes shift } \\
\mathrm{S}_{0} \rightarrow \mathrm{T}_{1} \rightarrow \mathrm{S}_{0} \\
\mathrm{eV}\end{array}$ \\
\hline $\mathrm{H} / \mathrm{OH} h h$ & B3LYP & $\begin{array}{l}4.207 \\
(295)\end{array}$ & $\begin{array}{l}2.125 \\
(583)\end{array}$ & 2.082 & $\begin{array}{l}3.932 \\
(315)\end{array}$ & 1.807 \\
\hline $\mathrm{H} / \mathrm{OH} h h$ & BHLYP & $\begin{array}{l}5.032 \\
(246)\end{array}$ & $\begin{array}{l}2.313 \\
(536)\end{array}$ & 2.719 & $\begin{array}{l}4.432 \\
(280)\end{array}$ & 2.119 \\
\hline $\mathrm{H} / \mathrm{OH} h h$ & B3LYP/COSMO & $\begin{array}{l}4.302 \\
(288)\end{array}$ & $\begin{array}{l}2.092 \\
(593)\end{array}$ & 2.210 & $\begin{array}{l}4.005 \\
(310)\end{array}$ & 1.913 \\
\hline $\mathrm{Me} / \mathrm{OMe}$ & B3LYP & $\begin{array}{l}4.127 \\
(300)\end{array}$ & $\begin{array}{l}2.994 \\
(423)\end{array}$ & 1.133 & $\begin{array}{l}3.774 \\
(329)\end{array}$ & 0.780 \\
\hline $\mathrm{Me} / \mathrm{OMe}$ & BHLYP & $\begin{array}{l}4.885 \\
(254)\end{array}$ & $\begin{array}{l}3.346 \\
(371)\end{array}$ & 1.539 & & \\
\hline${ }^{c} \mathrm{Pe} / \mathrm{OMe}$ & B3LYP & $\begin{array}{l}4.447 \\
(279)\end{array}$ & $\begin{array}{l}1.250 \\
(992)\end{array}$ & 3.197 & $\begin{array}{l}3.625 \\
(342)\end{array}$ & 2.375 \\
\hline${ }^{c} \mathrm{Pe} / \mathrm{OMe}$ & BHLYP & $\begin{array}{l}5.166 \\
(240)\end{array}$ & $\begin{array}{l}1.421 \\
(873)\end{array}$ & 3.745 & $\begin{array}{l}4.064 \\
(305)\end{array}$ & 2.643 \\
\hline${ }^{c} \mathrm{Pe} / \mathrm{OMe}$ & B3LYP/COSMO & $\begin{array}{l}4.459 \\
(278)\end{array}$ & $\begin{array}{l}2.211 \\
(561)\end{array}$ & 2.248 & $\begin{array}{l}3.958 \\
(313)\end{array}$ & 1.747 \\
\hline${ }^{c} \mathrm{Pe} / \mathrm{OMe}$ & BHLYP/COSMO & $\begin{array}{l}5.145 \\
(241)\end{array}$ & $\begin{array}{l}2.069 \\
(599)\end{array}$ & 3.076 & $\begin{array}{l}4.055 \\
(306)\end{array}$ & 1.986 \\
\hline $\mathrm{H} / \mathrm{OH} h t$ & B3LYP & $\begin{array}{l}4.262 \\
(291)\end{array}$ & $\begin{array}{l}2.978 \\
(416)\end{array}$ & 1.284 & $\begin{array}{l}3.917 \\
(317)\end{array}$ & 0.939 \\
\hline $\mathrm{H} / \mathrm{OH} h t$ & BHLYP & $\begin{array}{l}5.111 \\
(243)\end{array}$ & $\begin{array}{l}3.473 \\
(357)\end{array}$ & 1.638 & $\begin{array}{l}4.432 \\
(280)\end{array}$ & 0.959 \\
\hline $\mathrm{H} / \mathrm{OH} h h$ & $\mathrm{ADC}(2)$ & $\begin{array}{l}3.961 \\
(313)\end{array}$ & $\begin{array}{l}2.130 \\
(582)\end{array}$ & 1.831 & & \\
\hline $\mathrm{H} / \mathrm{OH} h h$ & $\operatorname{ADC}(2) / \mathrm{COSMO}$ & $\begin{array}{l}4.517 \\
(274)\end{array}$ & $\begin{array}{l}2.069 \\
(599)\end{array}$ & 2.448 & & \\
\hline $\mathrm{H} / \mathrm{OH} h h$ & $\mathrm{CC} 2$ & $\begin{array}{l}4.639 \\
(267)\end{array}$ & $\begin{array}{l}2.391 \\
(519)\end{array}$ & 2.248 & $\begin{array}{l}4.325 \\
(287)\end{array}$ & 1.934 \\
\hline
\end{tabular}


sorption band lies at $316 \mathrm{~nm}$. The wavelength of the maximum of the broad emission band is $679 \mathrm{~nm} .{ }^{16}$ These energy are in qualitative agreement with the calculated absorption and emission wavelengths of the $\left[\mathrm{Au}_{3}\left({ }^{c} \mathrm{Pe}=\mathrm{COMe}\right)_{3}\right]_{2}$ dimer, which are in the range of 240-279 $\mathrm{nm}$ and 561-992 nm, respectively, at the employed levels of theory. The ab initio correlated calculations yielded somewhat larger excitation energies than obtained at the B3LYP level, whereas essentially the same emission energies were obtained at the DFT and ab initio levels of theory. The calculated absorption and emission energies for $\left[\mathrm{Au}_{3}(\mathrm{HN}=\mathrm{COH})_{3}\right]_{2}$ are generally in good agreement with the absorption and emission energies of the hexagonal solid-state structure of $\left.\left[\mathrm{Au}_{3}(\mathrm{MeN}=\mathrm{COMe})_{3}\right]\right]^{8,14}$

Comparison of the absorption and emission energies calculated at the DFT level with the ones obtained at the $\mathrm{CC} 2$ and $\mathrm{ADC}(2)$ levels of theory shows that the B3LYP calculation slightly underestimate the excitation energies with respect to $\mathrm{CC} 2$ but overestimates it as compared to the value calculated at the $\mathrm{ADC}(2)$ level. The BHLYP calculations yielded slightly higher excitation energies than obtained at the $\mathrm{CC} 2$ level of theory.

The triplet excitation energies calculated at the B3LYP level for the optimized groundstate structures of $\left[\mathrm{Au}_{3}(\mathrm{HN}=\mathrm{COH})_{3}\right]$ and $\left[\mathrm{Au}_{3}(\mathrm{MeN}=\mathrm{COMe})_{3}\right]$ are $3.932 \mathrm{eV}$ and $3.774 \mathrm{eV}$, respectively, which are about $0.3 \mathrm{eV}$ smaller than the corresponding singlet excitation energies. The singlet-triplet splitting of $\left[\mathrm{Au}_{3}(\mathrm{HN}=\mathrm{COH})_{3}\right]$ is also $0.3 \mathrm{eV}$ at the $\mathrm{CC} 2$ level. The singlet-triplet splittings of the dimers can be obtained as the differences between the Stokes shifts of the $\mathrm{S}_{0} \rightarrow \mathrm{S}_{1} \cdots \mathrm{T}_{1} \rightarrow \mathrm{S}_{0}$ and $\mathrm{S}_{0} \rightarrow \mathrm{T}_{1} \rightarrow \mathrm{S}_{0}$ absorption-emission processes in Table 6.

\subsection{Absorption and emission energies of $\left[\mathrm{Au}_{3}(\mathrm{HN}=\mathrm{COH})_{3}\right]_{n}$ stacks}

For the small stacks with two, three, and four gold trimer units studied in this work, the alternating head-tail $(h t)$ conformation was the most stable structure. The absorption and emission energies calculated for dimers, trimers and tetramers of $\left[\mathrm{Au}_{3}(\mathrm{HN}=\mathrm{COH})_{3}\right]$ with the $h t$ structures are summarized in Table 7. For the dimer, the first singlet excitation energies are very similar for the head-head $(h h)$ and $h t$ structures, whereas the emission energy is 
Table 7: The transition energies and the corresponding wavelengths $(\lambda)$ for the $S_{0} \rightarrow S_{1}$ and $\mathrm{T}_{1} \rightarrow \mathrm{S}_{0}$ processes (in $\mathrm{eV}$ and in $\mathrm{nm}$ ) of the $\left[\mathrm{Au}_{3}(\mathrm{HN}=\mathrm{COH})_{3}\right]$ dimers, trimers and tetramers with alternating head-tail $(h t)$ configuration are listed. The Stokes shifts for the $\mathrm{S}_{0} \rightarrow \mathrm{S}_{1} \cdots \mathrm{T}_{1} \rightarrow \mathrm{S}_{0}$ absorption-emission process (in eV) are also reported. The excitation energies have been calculated at the B3LYP and BHLYP levels using the def2-TZVP basis set. The red regions corresponds to a larger electron density for the excited state. The hole density of the exciton is shown in blue.

\begin{tabular}{llccccc}
\hline \hline System & Method & $\begin{array}{c}\mathrm{S}_{0} \rightarrow \mathrm{S}_{1} \\
\mathrm{eV}\end{array}$ & $\begin{array}{c}\mathrm{T}_{1} \rightarrow \mathrm{S}_{0} \\
\mathrm{eV}\end{array}$ & $\begin{array}{c}\mathrm{S}_{0} \rightarrow \mathrm{S}_{1} \\
\mathrm{~nm}\end{array}$ & $\begin{array}{c}\mathrm{T}_{1} \rightarrow \mathrm{S}_{0} \\
\mathrm{~nm}\end{array}$ & $\begin{array}{c}\text { Stokes shift } \\
\mathrm{eV}\end{array}$ \\
\hline Dimer $h t$ & B3LYP & 4.262 & 2.978 & 291 & 416 & 1.284 \\
Dimer $h t$ & BHLYP & 5.111 & 3.473 & 243 & 357 & 1.638 \\
Trimer $h t h$ & B3LYP & 3.864 & 2.531 & 321 & 490 & 1.333 \\
Trimer $h t h$ & BHLYP & 4.683 & 3.091 & 265 & 401 & 1.592 \\
Tetramer $h t h t$ & B3LYP & 3.733 & 2.345 & 332 & 529 & 1.388 \\
Tetramer $h t h t$ & BHLYP & 4.468 & 2.950 & 277 & 420 & 1.518 \\
\hline \hline
\end{tabular}

blue shifted for the $h t$ dimer as compared to the $h h$ one. The $h h$ conformer has apparently a larger electron density between the monomers in the excited state than the $h t$ one, despite it possesses a higher ground-state energy than the alternating $h t$ conformer.

Calculations on the oligomers show that the absorption energy is smaller for the larger stacks. The excitation energy is approaching a solid state value of about $3.5 \mathrm{eV}$ (350 nm) at the B3LYP level. The absorption energies calculated at the BHLYP level converge towards c. $4.2 \mathrm{eV}(295 \mathrm{~nm})$ for the solid-state structure. The B3LYP triplet excitation energy for the tetramer model attains nearly matching values to experimental solid-state excitation data that portray to the visible region. ${ }^{16}$ Calculations on the dimers suggest that these values are upper and lower bounds for the absorption energy for the solid-state material. At the B3LYP level, the $S_{0} \rightarrow \mathrm{S}_{1} \cdots \mathrm{T}_{1} \rightarrow \mathrm{S}_{0}$ Stokes shifts are about $1.3 \mathrm{eV}$ and almost independent of the size of the oligomers. BHLYP calculations yield absorption and emission energies as well as Stokes shifts that are somewhat larger than obtained at the B3LYP level. The calculations reproduce the experimental trend that the Stokes shifts decrease for larger clusters as compared to the dimers. An emission energy plateau is seen for the BHLYP $\mathrm{T}_{1} \rightarrow \mathrm{S}_{0}$ energies in Table 7, whereas the absorption energies continue to red shift when increasing 
the cluster size, which is consistent with the experimental findings that dimeric solids emit in the yellow-red with large Stokes shifts, whereas extended-chain stacks have smaller Stokes shifts and emit blue light.

\section{Solvoluminescence mechanism}

The hexagonal polymorph of $\left[\mathrm{Au}_{3}(\mathrm{MeN}=\mathrm{COMe})_{3}\right]$ displays solvoluminescence, that is, bright yellow light that is emitted when adding solvent to the crystals after they have been irradiated with near-UV light. ${ }^{8,9,14,16}$ The triclinic and monoclinic polymorphs are not solvoluminescent nor any of the other R/R variations in Refs. 14 and 16 . So far, the monoclinic $\left[\mathrm{Au}_{3}(\mathrm{MeN}=\mathrm{COMe})_{3}\right]$ crystalline form with ordered and disordered stacks is the only solvoluminescent trinuclear gold(I) material. Even the $\mathrm{Me} / \mathrm{O}^{n} \mathrm{Bu}$ structure with uniform ordered stacks does not display solvoluminescence. The phenomenon is known to be related to the stacking structure of the planar trinuclear gold(I) complexes in the solid state. ${ }^{8,9,11,15}$

Irradiation of the crystals creates long-lived excitons that are stored somewhere in the crystals. It is not elucidated where in the solid the excitation energy is stored. ${ }^{15}$ The present calculations suggest that the excitons are released from the solid and bind to dimers that are formed in the solution phase when the crystals are dissolved. Yellow light is emitted when the dissolved excited dimers return to the ground state and dissociates. The electron density of the exciton between the molecules increases the binding energy of the excited dimers leading to their stabilization. The absence of the solvoluminescence for the $\mathrm{Me} / \mathrm{O}^{n} \mathrm{Bu}$ structure might be due to the bulky ${ }^{n} \mathrm{Bu}$ substituents that hamper the formation of stable excited dimers in solution or the disordered stacks play a crucial role. Alternatively, the ${ }^{n} \mathrm{Bu}$ substituents prevent the exciton storage in the solid state. $\left[\mathrm{Au}_{3}\left(\mathrm{RN}=\mathrm{COR}^{\prime}\right)_{3}\right]$ materials with larger $\mathrm{R} / \mathrm{R}^{\prime}$ substituents might dissolve directly into monomers upon solvent contact, which would

explain why they are not solvoluminescent. The crystal structure of $\left[\mathrm{Au}_{3}(\mathrm{MeN}=\mathrm{COMe})_{3}\right]$ with staggered stacks seems to be the only trinuclear gold(I) complex that can store long- 
lived excitons in the solid state and form stable excited dimers in solution. The present calculations show that the dimers have a large Stokes shift with absorption in the UV and emission in the wave-length region of $500 \mathrm{~nm}$ to $600 \mathrm{~nm}$ corresponding to the yellow light of the solvoluminescence.

The dimers are known to absorb at higher energies and emit at lower energy than the extended stacks, as shown in Table 7 for the two extreme cases of ${ }^{c} \mathrm{Pe} / \mathrm{OMe}$ and $\mathrm{Me} / \mathrm{O}^{n} \mathrm{Bu}$, whereas the excitation spectra of the hexagonal Me/OMe polymorph are identical for the yellow and the blue emission bands. ${ }^{16}$ We hypothesize therefore that the energy stored in the stacks is transferred to the self-trapped dimer sites in the disordered stack; this energy is thereafter released upon solvent contact that leads to dissolution of dimers at high concentration near the surface. Dimerization of cyclotrimer molecules at high concentrations is not unusual, as known for other compositions. ${ }^{13}$

\section{Summary and conclusions}

We have computationally studied the molecular structures of stacked cyclic trinuclear gold(I) complexes $\left(\left[\mathrm{Au}_{3}\left(\mathrm{RN}=\mathrm{CR}^{\prime}\right)_{3}\right]_{n}\right.$ with $\left.n=1-4\right)$. The considered $\mathrm{R}$ and $\mathrm{R}^{\prime}$ substituents are $\mathrm{R}$ $=\mathrm{H}, \mathrm{Me},{ }^{c} \mathrm{Pe}, \mathrm{Ph}$ and $\mathrm{R}^{\prime}=\mathrm{OH}, \mathrm{OMe}$. The structure optimizations were performed at the TPSS-D3 and MP2 levels of theory.

For the $\left[\mathrm{Au}_{3}(\mathrm{HN}=\mathrm{COH})_{3}\right]_{2}$ dimer, the structure optimizations yielded a slided stacked structure, where the center of the monomers are shifted relatively to each other. The slided structure is at the MP2 level $32 \mathrm{~kJ} / \mathrm{mol}$ more stable than the staggered dimer. The eclipsed dimer structure lies $11 \mathrm{~kJ} / \mathrm{mol}$ above the staggered one. In the stacks, the monomers can be oriented in the head $(h)$ or tail $(t)$ direction. The slided alternating head-tail $(h t)$ structure of the $\left[\mathrm{Au}_{3}(\mathrm{HN}=\mathrm{COH})_{3}\right]_{2}$ dimer was found to be energetically lower than the corresponding head-head $(h h)$ structure. For the trimers and tetramers, the alternating $(h t h)$ and $(h t h t)$ structures are also the most stable conformations, which does not agree with interpretations 
of X-ray structures in a previous study. ${ }^{16}$

Optimizations of the molecular structure of $\left[\mathrm{Au}_{3}(\mathrm{MeN}=\mathrm{COMe})_{3}\right]_{n}$ yielded a novel conformation, in which the individual molecules are tilted and slided relatively to each other leading to a helical stack with short $\mathrm{Au}-\mathrm{Au}$ distances. The structure is reminiscent of the recently reported experimental structure forming helical columns with molecules that are mutually rotated by about $40^{\circ} .^{28}$ The interaction between aromatic substituents leads to a planar and prismatic structure of the $\left[\mathrm{Au}_{3}(\mathrm{PhN}=\mathrm{COMe})_{3}\right]_{4}$ tetramer with short intermolecular $\mathrm{Au}-\mathrm{Au}$ distances, due to the additional $\pi-\pi$ interactions between the phenyls. Due to the steric interaction of the bulky substituents such as ${ }^{c} \mathrm{Pe}$, the molecules form dimer structures with a rather short intermolecular distance. The intermolecular distance between the dimers is significantly longer. The molecules have a slided structure with respect to each other leading to helical stacks.

Optimization of the molecular structure of the triplet state of the $\left[\mathrm{Au}_{3}(\mathrm{HN}=\mathrm{COH})_{3}\right]$ dimer yields a tilted and slided structure with one short $\mathrm{Au}-\mathrm{Au}$ distance of $2.860 \AA$. The slided structure of the triplet state is similar to the ground-state structure. However, the monomers are less parallel relatively to each other than in the ground-state structure. The short $\mathrm{Au}-\mathrm{Au}$ distance stabilizes the exciton leading to a significantly smaller excitation energy than for the ground-state structure resulting in very large Stokes shifts.

Excitation energies were calculated for $\left[\mathrm{Au}_{3}\left(\mathrm{RN}=\mathrm{CR}^{\prime}\right)_{3}\right]$ and $\left[\mathrm{Au}_{3}\left(\mathrm{RN}=\mathrm{CR}^{\prime}\right)_{3}\right]_{2}$ with $\mathrm{R}$ $=\mathrm{H}, \mathrm{Me},{ }^{c} \mathrm{Pe}$ and $\mathrm{R}^{\prime}=\mathrm{OH}$ and OMe at the B3LYP level using the optimized molecular structures of the singlet ground state. Solvent effects estimated using COSMO are less than $\pm 0.1 \mathrm{eV}$. Luminescence spectra were obtained by calculating the excitation energy of the first triplet state using the molecular structure optimized for the lowest triplet state.

Excitation energies of $\left[\mathrm{Au}_{3}(\mathrm{HN}=\mathrm{COH})_{3}\right]$ and $\left[\mathrm{Au}_{3}(\mathrm{HN}=\mathrm{COH})_{3}\right]_{2}$ calculated at the $\mathrm{CC} 2$ and $\mathrm{ADC}(2)$ levels of theory agree well with the ones calculated at the DFT level using B3LYP and BHLYP functionals. The calculated absorption and emission energies reproduce experimental trends with absorption in the near-UV region and extremely large Stokes shifts 
leading to luminescence in the yellow range. The present calculations suggest that solvoluminescence involves excited stacked dimers that emit yellow light when they are dissolved, since monomers do not irradiate in that energy range.

\section{Acknowledgements}

This research has been supported by the Academy of Finland through projects (268251, 266227, and 275845) HR thanks the University of Helsinki for support. DS thanks Magnus Ehrnrooth Foundation, the Swedish Cultural Foundation in Finland, the Fulbright Foundation, and the Alexander von Humboldt Stiftung for financial support during his sabbatical leave. ST thanks Ruth och Nils-Erik Stenbäcks stiftelse for financial support. M.A.O. gratefully acknowledges support to his group with contributions by the Robert A. Welch Foundation (Grant B-1542) and the U. S. National Science Foundation (NSF Grants CHE-1413641 and CHE-1545934). CSC - the Finnish IT Center for Science - is acknowledged for computational resources. We thank Prof. R. Hoffmann, (Cornell University), P. Pyykkö (University of Helsinki), and Dr. P. Zaleski-Ejgierd (Polish Academy of Sciences, Warsaw) for helpful discussions.

\section{Supporting Information Available}

Electronic supplementary information (ESI) available: The Cartesian coordinates of the investigated molecules are reported as supporting information.

\section{References}

(1) Schmidbaur, H. The Fascinating Implications of New Results in Gold Chemistry. Gold Bull. 1990, 23, 11-21. 
(2) Shriver, D. F.; Kaesz, H. D.; Adams, R. D. The Chemistry of Metal Cluster Complexes; VCH Publishers, Inc: New York, 1990.

(3) Pyykkö, P. Theoretical Chemistry of Gold. Angew. Chem. Int. Ed. 2004, 43, 44124456.

(4) Vaughan, L. G. Organogold Chemistry. III. 2-Pyridylgold(I). J. Am. Chem. Soc. 1970, 92, 730-731.

(5) Minghetti, G.; Bonati, F. Trimeric (Alkoxy)(alkylimino)methylgold(I) Compounds, $\left[(\mathrm{RO})\left(\mathrm{R}^{\prime} \mathrm{N}=\right) \mathrm{CAu}\right]_{3}$. Inorg. Chem. 1974, 13, 1600-1602.

(6) Murray, H. H.; Raptis, R. G.; Fackler, J. P. Syntheses and X-ray Structures of Group 11 Pyrazole and Pyrazolate Complexes. X-ray Crystal Structures of Bis(3,5-diphenylpyrazole)copper(II) Dibromide, Tris ( $\mu$-3,5-diphenylpyrazolatoN,N')trisilver(I)-2-tetrahydrofuran, Tris( $\mu$-3,5-diphenylpyrazolato-N,N')trigold(I), and Hexakis( $\mu$-3,5-diphenylpyrazolato-N,N')hexagold(I). Inorg. Chem. 1988, 27, 26-33.

(7) Raptis, R. G.; Fackler, J. P. Structure of Tris $(\mu$-3,5-diphenylpyrazolatoN,N')tricopper(I). Structural Comparisons with the Silver(I) and Gold(I) Pyrazolate Trimers. Inorg. Chem. 1988, 27, 4179-4182.

(8) Vickery, J. C.; Olmstead, M. M.; Fung, E. Y.; Balch, A. L. Solvent-Stimulated Luminescence from the Supramolecular Aggregation of a Trinuclear Gold(I) Complex that Displays Extensive Intermolecular Au...Au Interactions. Angew. Chem. Int. Ed. 1997, 36, 1179-1181.

(9) Fung, E. Y.; Olmstead, M. M.; Vickery, J. C.; Balch, A. L. Glowing Gold Rings: Solvoluminescence from Planar Trigold(I) Complexes. Coord. Chem. Rev. 1998, 171, 151-159. 
(10) Fernández, E. J.; Gimeno, M. C.; Laguna, A.; López-de-Luzuriaga, J. M.; Monge, M.; Pyykkö, P.; Sundholm, D. Luminescent Characterization of Solution Oligomerization Process Mediated Gold-Gold Interactions. DFT Calculations on $\left[\mathrm{Au}_{2} \mathrm{Ag}_{2} \mathrm{R}_{4} \mathrm{~L}_{2}\right]_{n}$ Moieties. J. Am. Chem. Soc. 2000, 122, 7287-7293.

(11) Olmstead, M. M.; Jiang, F.; Attar, S.; Balch, A. L. Alteration of the Aurophilic Interactions in Trimeric Gold(I) Compounds through Charge Transfer. Behavior of Solvoluminescent $\mathrm{Au}_{3}(\mathrm{MeNCOMe})_{3}$ in the Presence of Electron Acceptors. J. Am. Chem. Soc. 2001, 123, 3260-3267.

(12) White-Morris, R. L.; Olmstead, M. M.; Jiang, F.; Tinti, D. S.; Balch, A. L. Remarkable Variations in the Luminescence of Frozen Solutions of $\left[\mathrm{Au}\left\{\mathrm{C}(\mathrm{NHMe})_{2}\right\}_{2}\right]\left(\mathrm{PF}_{6}\right) \cdot 0.5$ (Acetone). Structural and Spectroscopic Studies of the Effects of Anions and Solvents on Gold(I) Carbene Complexes. J. Am. Chem. Soc. 2002, 124, 2327-2336.

(13) Yang, C.; Messerschmidt, M.; Coppens, P.; Omary, M. A. Trinuclear Gold(I) Triazolates: A New Class of Wide-Band Phosphors and Sensors. Inorg. Chem. 2006, 45, 6592-6594.

(14) White-Morris, R. L.; Olmstead, M. M.; Attar, S.; Balch, A. L. Intermolecular Interactions in Polymorphs of Trinuclear Gold(I) Complexes: Insight into the Solvoluminescence of $\mathrm{Au}_{3}(\mathrm{MeNCOMe})_{3}$. Inorg. Chem. 2005, 44, 5021-5029.

(15) Winkler, K.; Wysocka-Zołopa, M.; Rećko, K.; Dobrzyński, L.; Vickery, J. C.; Balch, A. L. Formation of a Partially Oxidized Gold Compound by Electrolytic Oxidation of the Solvoluminescent Gold(I) Trimer, $\mathrm{Au}_{3}(\mathrm{MeNCOMe})_{3}$. Inorg. Chem. 2009, 48, 1551-1558.

(16) McDougald, Jr., R. N.; Chilukuri, B.; Jia, H.; Perez, M. R.; Rabaá, H.; Wang, X.; Nesterov, V. N.; Cundari, T. R.; Gnade, B. E.; Omary, M. A. Molecular and Elec- 
tronic Structure of Cyclic Trinuclear Gold(I) Carbeniate Complexes: Insights for Structure/Luminescence/Conductivity Relationships. Inorg. Chem. 2014, 53, 7485-7499.

(17) Scherbaum, F.; Grohmann, A.; Huber, B.; Schmidbaur, H. Aurophilicity as a Consequence of Relativistic Effects - the Hexakis(triphenylphosphaneaurio)methane Dication $\left[\mathrm{Ph}_{3} \mathrm{PAu}\right]^{2+}$. Angew. Chem. Int. Ed. Engl. 1988, 27, 1544-1546.

(18) Mendizabal, F.; Reyes, D.; Olea-Azar, C. Complexes Self-Associate by Hydrogen Bonding and Metallophilic Attraction: Theoretical Study. Int. J. Quant. Chem. 2006, 106, 906-912.

(19) Mendizabal, F.; Aguilera, B.; Olea-Azar, C. Theoretical Study on Electronic Spectra and Aurophilic Attraction in Complexes. Chem. Phys. Letters 2007, 447, 345-351.

(20) Muñoz-Castro, A.; Mac-Leod Carey, D.; Arratia-Pérez, R. Electronic Structure, Molecular Properties and Electronic Currents of the Luminescent $\left[\mathrm{Au}_{3}\left(\mathrm{CH}_{3} \mathrm{~N} @ \mathrm{COCH}_{3}\right)_{3}\right]$ Cluster. Chem. Phys. Letters 2009, 474, 290-293.

(21) Mendizabal, F. Theoretical Study of $\mathrm{Au}_{3}\left(\mathrm{CH}_{3} \mathrm{NCOCH}_{3}\right)_{3 n} \cdot 2,4$,7-trinitro-9-fluorenone $(\mathrm{n}=1,2)$ Complexes. Int. J. Quant. Chem. 2010, 110, 1279-1286.

(22) Mendizabal, F.; Salazar, R. Theoretical Study on Electronic Spectra and Interaction in $\left[\mathrm{Au}_{3}\right]-\mathrm{L}-\left[\mathrm{Au}_{3}\right]\left(\mathrm{L}=\mathrm{C}_{6} \mathrm{~F}_{6}, \mathrm{Ag}^{+}\right)$Complexes. J. Mol. Model. 2013, 19, 1973-1979.

(23) Rodríguez-Castillo, M.; Monge, M.; López-de-Luzuriaga, J. M.; Olmos, M. E.; Laguna, A.; Mendizabal, F. Theoretical Study of the Closed-Shell $d^{10}-d^{10} \mathrm{Au}(\mathrm{I})-\mathrm{Cu}(\mathrm{I})$ Attraction in Complexes in Extended Unsupported Chains. Comp. Theor. Chem. 2011, 965, 163-167.

(24) Burgos, D.; Olea-Azar, C.; Mendizabal, F. Theoretical Study of the Local Reactivity of Electrophiles of the Type $\mathrm{MPR}_{3}^{+}(\mathrm{M}=\mathrm{Cu}, \mathrm{Ag}, \mathrm{Au} ; \mathrm{R}=-\mathrm{H},-\mathrm{Me},-\mathrm{Ph})$. J. Mol. Model. 2012, 18, 2021-2029. 
(25) Sun, Y.; Giebink, N. C.; Kanno, H.; Ma, B.; Thompson, M. E.; Forrest, S. R. Management of Singlet and Triplet Excitons for Efficient White Organic Light-Emitting Devices. Nature 2006, 440, 908-912.

(26) Pyykkö, P. Strong Closed-Shell Interactions in Inorganic Chemistry. Chem. Rev. 1997, $97,597-636$.

(27) Schmidbaur, H.; Schier, A. Aurophilic Interactions as a Subject of Current Research: an Up-Date. Chem. Soc. Rev. 2012, 41, 370-412.

(28) Beltrán, E.; Barberá, J.; Serrano, J. L.; Elduque, A.; Giménez, R. Chiral Cyclic Trinuclear Gold(I) Complexes with a Helical Columnar Phase. Eur. J. Inorg. Chem. 2014, 2014, 1165-1173.

(29) Elbjeirami, O.; Omary, M. A.; Stender, M.; Balch, A. L. Anomalous StructureLuminescence Relationship in Phosphorescent Gold(i) Isonitrile Neutral Complexes. Dalton Trans. 2004, 3173-3175.

(30) Elbjeirami, O.; Gonser, M. W. A.; Stewart, B. N.; Bruce, A. E.; Bruce, M. R. M.; Cundari, T. R.; Omary, M. A. Luminescence, Structural, and Bonding Trends Upon Varying the Halogen in Isostructural Aurophilic Dimers. Dalton Trans. 2009, 15221533.

(31) Kasha, M. Characterization of Electronic Transitions in Complex Molecules. Discuss. Faraday Soc. 1950, 9, 14-19.

(32) Eichkorn, K.; Weigend, F.; Treutler, O.; Ahlrichs, R. Auxiliary Basis Sets for Main Row Atoms and Transition Metals and Their Use to Approximate Coulomb Potentials. Theoret. Chem. Acc. 1997, 97, 119-124.

(33) Tao, J.; Perdew, J. P.; Staroverov, V. N.; Scuseria, G. E. Climbing the Density Func- 
tional Ladder: Nonempirical Meta-Generalized Gradient Approximation Designed for Molecules and Solids. Phys. Rev. Letters 2003, 91, 146401.

(34) Grimme, S.; Antony, J.; Ehrlich, S.; Krieg, H. A Consistent and Accurate Ab Initio Parametrization of Density Functional Dispersion Correction (DFT-D) for the 94 Elements H-Pu. J. Chem. Phys. 2010, 132, 154104.

(35) Weigend, F.; Häser, M. RI-MP2: First Derivatives and Global Consistency. Theoret. Chem. Acc. 1997, 97, 331-340.

(36) Weigend, F.; Häser, M.; Patzelt, H.; Ahlrichs, R. RI-MP2: Optimized Auxiliary Basis Sets and Demonstration of Efficiency. Chem. Phys. Letters 1998, 294, 143-152.

(37) Köhn, A.; Hättig, C. Analytic Gradients for Excited States in the Coupled-Cluster Model CC2 Employing the Resolution-of-the-Identity Approximation. J. Chem. Phys. 2003, 119, 5021-5036.

(38) Hättig, C. Structure Optimizations for Excited States with Correlated Second-Order Methods: CC2 and ADC(2). Adv. Quantum Chem. 2005, 50, 37-60.

(39) Weigend, F.; Ahlrichs, R. Balanced Basis Sets of Split Valence, Triple Zeta Valence and Quadruple Zeta Valence Quality for H to Rn: Design and Assessment of Accuracy. Phys. Chem. Chem. Phys. 2005, 7, 3297-3305.

(40) Andrae, D.; Häussermann, U.; Dolg, M.; Stoll, H.; Preuss, H. Energy-Adjusted Ab Initio Pseudopotentials for the Second and Third Row Transition Elements. Theor. Chim. Acta 1990, 77, 123-141.

(41) Figgen, D.; Rauhut, G.; Dolg, M.; Stoll, H. Energy-Consistent Pseudopotentials for Group 11 and 12 Atoms: Adjustment to Multi-Configuration Dirac-Hartree-Fock data. Chem. Phys. 2005, 311, 227-244. 
(42) Boys, S.; Bernardi, F. The Calculation of Small Molecular Interactions by the Differences of Separate Total Energies. Some Procedures with Reduced Errors. Mol. Phys. 1970, 19, 553-566.

(43) Casida, M.; Huix-Rotllant, M. Progress in Time-Dependent Density-Functional Theory. Annu. Rev. Phys. Chem. 2012, 63, 287-323.

(44) Bauernschmitt, R.; Ahlrichs, R. Treatment of Electronic Excitations within the Adiabatic Approximation of Time Dependent Density Functional Theory. Chem. Phys. Letters 1996, 256, 454-464.

(45) Becke, A. D. Density-Functional Thermochemistry. III. The Role of Exact Exchange. J. Chem. Phys. 1993, 98, 5648-5652.

(46) Lee, C.; Yang, W.; Parr, R. G. Development of the Colle-Salvetti Correlation-Energy Formula into a Functional of the Electron Density. Phys. Rev. B 1988, 37, 785-789.

(47) Vosko, S. H.; Wilk, L.; Nusair, M. Accurate Spin-Dependent Electron Liquid Correlation Energies for Local Spin-Density Calculations - a Critical Analysis. Can. J. Phys 1980, 58, 1200-1211.

(48) Becke, A. D. A New Mixing of Hartree-Fock and Local Density-Functional Theories. J. Chem. Phys. 1993, 98, 1372-1377.

(49) Christiansen, O.; Koch, H.; Jørgensen, P. The 2nd-Order Approximate Coupled-Cluster Singles and Doubles Model CC2. Chem. Phys. Letters 1995, 243, 409-418.

(50) Schirmer, J. Beyond the Random-Phase Approximation: A New Approximation Scheme for the Polarization Propagator. Phys. Rev. A 1982, 26, 2395-2416.

(51) Hättig, C.; Weigend, F. CC2 Excitation Energy Calculations on Large Molecules Using the Resolution of the Identity Approximation. J. Chem. Phys. 2000, 113, 5154-5161. 
(52) Klamt, A.; Schüürmann, G. COSMO - A New Approach to Dielectric Screening in Solvents with Explicit Expressions for the Screening Energy and its Gradient. J. Chem. Soc. Perkin Trans. 2 1993, , 799-805.

(53) Schäfer, A.; Klamt, A.; Sattel, D.; Lohrenz, J. C. W.; Eckert, F. COSMO Implementation in TURBOMOLE: Extension of an Efficient Quantum Chemical Code towards Liquid Systems. Phys. Chem. Chem. Phys. 2000, 2, 2187-2193.

(54) Ahlrichs, R.; Bär, M.; Häser, M.; Horn, H.; Kölmel, C. Electronic Structure Calculations on Workstation Computers: The Program System TURBOMOLE. Chem. Phys. Letters 1989, 162, 165-169.

(55) Furche, F.; Ahlrichs, R.; Hättig, C.; Klopper, W.; Sierka, M.; Weigend, F. Turbomole. WIREs Comput. Mol. Sci. 2014, 4, 91-100.

(56) ChemBioDraw Version 16, PerkinElmer Informatics.

(57) Avogadro: an Open-Source Molecular Builder and Visualization Tool. Version 1.1.1 http://avogadro.cc/.

(58) Hanwell, M. D.; Curtis, D. E.; Lonie, D. C.; Vandermeersch, T.; Zurek, E.; Hutchison, G. R. Avogadro: An Advanced Semantic Chemical Editor, Visualization, and Analysis Platform. J. Cheminf. 2012, 4, 17.

(59) Williams, T.; Kelley, C.; et. al., 2016; Gnuplot 5.0: an Interactive Plotting Program. http://www.gnuplot.info/.

(60) Laaksonen, L. A Graphics Program for the Analysis and Display of Molecular Dynamics Trajectories. J. Mol. Graph. 1992, 10, 33-34.

(61) Bergman, D. L.; Laaksonen, L.; Laaksonen, A. Visualization of Solvation Structures in Liquid Mixtures. J. Mol. Graph. Model. 1997, 15, 301-306. 
(62) Muñoz-Castro, A.; Mac-Leod Carey, D.; Arratia-Pérez, R. Calculated Molecular Properties of Triangular Tribenzo and Perfluoro-Tribenzo Trimercuronin Macrocycles. J. Phys. Chem. A 2010, 114, 666-672.

(63) Bauernschmitt, R.; Ahlrichs, R. Stability Analysis for Solutions of the Closed Shell Kohn-Sham Equation. J. Chem. Phys. 1996, 104, 9047-9052.

(64) Pabst, M.; Sundholm, D.; Köhn, A. Ab Initio Studies of Triplet-State Properties for Organic Semiconductor Molecules. J. Phys. Chem. C 2012, 116, 15203-15217. 


\section{Graphical TOC Entry}

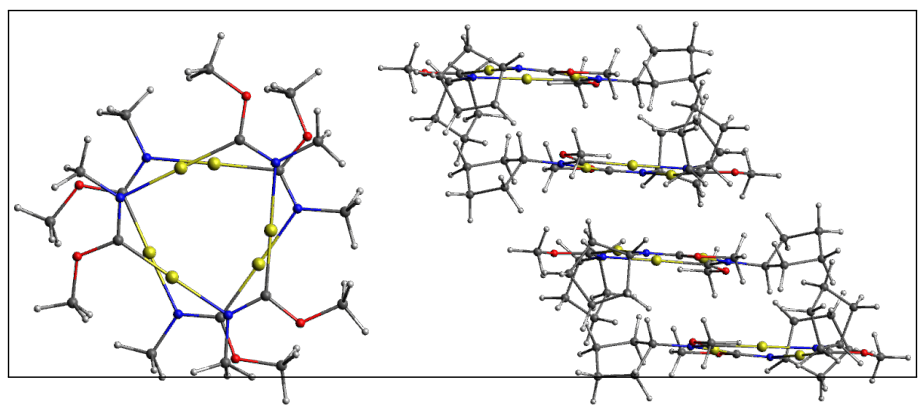

Molecular structures as well as absorption and emission energies of stacked cyclic trinuclear gold $(\mathrm{I})$ complexes $\left[\mathrm{Au}_{3}\left(\mathrm{RN}=\mathrm{CR}^{\prime}\right)_{3}\right]_{n}$, with $n=$ $1-4$, where $\mathrm{R}$ is hydrogen, methyl, cyclopentyl, phenyl, and $\mathrm{R}^{\prime}$ is hydroxy and methoxy have been studied at first-principle computational levels of theory. Calculated absorption and luminescence spectra qualitatively agree with the measured spectra and Stokes shifts. A solvoluminescence mechanism is proposed. 